\title{
Educación para el desarrollo sostenible: análisis del Centro de Secundaria Iturrama
}

\section{Education for Sustainable Development: Analysis of the Iturrama High \\ School \\ Educação para o desenvolvimento sustentável: análise do Centro Secundário Iturrama}

Maialen Muguerza Amigorena

Universitat Jaume I, Departamento de Lenguajes y Sistemas Informáticos, Grupo de Investigación en Integración y Re-Ingeniería de Sistemas (IRIS), España maialen_ma@hotmail.com https://orcid.org/0000-0003-2904-2602

\section{Ricardo Chalmeta*}

Universitat Jaume I, Departamento de Lenguajes y Sistemas Informáticos, Grupo de Investigación en Integración y Re-Ingeniería de Sistemas (IRIS), España rchalmet@uji.es http://orcid.org/0000-0001-5490-7802

*Autor de correspondencia

\section{Resumen}

En este artículo, en línea con la propuesta de la Unesco de utilizar la educación como herramienta para lograr la sostenibilidad, se muestra el análisis realizado a un centro de educación secundaria público español sobre cómo se trabajan los Objetivos para el Desarrollo Sostenible (ODS) tanto a nivel del centro como de asignaturas. Se explica el proceso de investigación realizado para la recopilación de la información necesaria y los resultados obtenidos de los cuestionarios realizados a los principales actores en el centro: la dirección, el profesorado y el alumnado. Finalmente, teniendo en cuenta los resultados, se realiza una propuesta de mejora que permite alinear la estrategia de la dirección del centro con la educación para la sostenibilidad, y transformarla en una serie de planes de 
acción concretados en diferentes proyectos que involucran a los profesores y alumnos en la consecución de todos los ODS. El trabajo presentado aquí podría tomarse como base para futuros análisis y mejoras similares en otros centros, teniendo en cuenta la metodología seguida en este trabajo y los cuestionarios realizados.

Palabras clave: competencia, desarrollo, educación, gestión educacional, objetivos, sostenibilidad.

\section{Abstract}

In this article, in line with UNESCO's proposal to use education as a tool to achieve sustainability, an analysis carried out at a Spanish public secondary education center on how the Sustainable Development Goals (SDG) are worked both at the center and subject level is presented. Three questionnaires were prepared which, together with a semistructured interview, allowed to identify how many SDG and competencies each subject works and the degree to which each SDG is worked in each training cycle. Taking into account the results obtained, an improvement proposal was made to align the strategy of the secondary school's managers with education for sustainability and transform it into a series of action plans specified in different projects that involve teachers and students in the achievement of all the SDG. The work presented here could be taken as the basis for future analyzes and similar improvements in other centers, taking into account the methodology followed in this work and the questionnaires carried out.

Keywords: skills, sustainable education, educational management, development goals, sustainability.

\section{Resumo}

Neste artigo, em linha com a proposta da Unesco de utilizar a educação como ferramenta para a sustentabilidade, apresenta-se a análise realizada em um centro público de ensino médio espanhol sobre como são trabalhados os Objetivos de Desenvolvimento Sustentável (ODS) em ambos. ao nível do centro e dos sujeitos. São explicados o processo de pesquisa realizado para coletar as informações necessárias e os resultados obtidos a partir dos questionários feitos aos principais atores do centro: a gestão, os professores e os alunos. Por fim, tendo em conta os resultados, é feita uma proposta de melhoria que permite alinhar a estratégia de gestão do centro com a educação para a sustentabilidade, transformando-a num conjunto de planos de ação concretos em 
diferentes projetos que envolvem docentes e alunos na realização de todos os ODS. O trabalho aqui apresentado poderá servir de base a futuras análises e melhorias semelhantes em outros centros, tendo em conta a metodologia seguida neste trabalho e os questionários realizados.

Palavras-chave: competência, desenvolvimento, educação, gestão educacional, objetivos, sustentabilidade.

Fecha Recepción: Mayo 2020

Fecha Aceptación: Octubre2020

\section{Introducción}

La actividad desmesurada del ser humano ha acarreado consecuencias medioambientales, sociales y económicas que ponen en entredicho el futuro del planeta. Con intención de redirigir nuestro camino, y asegurar un futuro para todos y todas, en 2015 la Organización de las Naciones Unidas para la Educación, la Ciencia y la Cultura (Unesco) (ONU, 2015) aprobó la Agenda 2030 para el Desarrollo Sostenible. Dicha agenda incluye 17 objetivos, denominados Objetivos para el Desarrollo Sostenible (ODS), que deben ser alcanzados para el 2030. Dentro de estos, el ODS 4 busca garantizar una educación inclusiva, equitativa y de calidad y promover oportunidades de aprendizaje durante toda la vida para todos los seres humanos. Sin duda, la educación es la mejor herramienta para que se dé el verdadero y necesario cambio para lograr estos ambiciosos objetivos. Por lo tanto, juega un doble papel en la consecución de los ODS: objetivo a ser cumplido y mecanismo para lograr los 16 objetivos restantes.

Este planteamiento queda perfectamente reflejado en la siguiente declaración de Irina Bokova (citada en Unesco, 2017), anterior directora general de la Unesco:

Se necesita un cambio fundamental en la forma en que pensamos sobre el rol de la educación en el Desarrollo mundial, porque tiene un efecto catalizador en el bienestar de los individuos y el futuro de nuestro planeta. (...) Ahora más que nunca, la educación tiene la responsabilidad de estar a la par de los desafíos y las aspiraciones del siglo XXI, y de promover los tipos correctos de valores y habilidades que llevarán al crecimiento sostenible e inclusivo y a una vida pacífica juntos (p. 7).

Este cambio de paradigma en la visión e importancia de la educación como herramienta para el desarrollo sostenible ha sido refrendado por diferentes investigadores (Vilches, 2012; Watson, 2017). Las aportaciones se han centrado hasta el momento en 
resaltar la importancia de la formación del profesorado en esta materia (Solís, 2015), en la medición del nivel de formación del profesorado (Anyolo, 2018; Rabiatul, 2012), en la definición de propuestas de actividades para transmitir al alumnado conocimiento sobre los ODS (Aneas et al., 2017) y en las percepciones del alumnado de ámbito universitario (García y Rendón, 2018).

Sin embargo, no existe en nuestro conocimiento ninguna investigación como la mostrada en este artículo que 1) analice el trabajo realizado para alcanzar los ODS en un centro de secundaria desde un punto de vista holístico, tanto a nivel de centro como en cada asignatura, considerando las percepciones de la dirección, el cuerpo docente y alumnado, y 2) se propongan mejoras que permitan alinear la estrategia de la dirección del centro con la educación para la sostenibilidad, y transformarla en una serie de planes de acción concretados en diferentes proyectos que involucran a los profesores y alumnos en la consecución de todos los ODS.

Por lo tanto, el trabajo aquí presentado podría tomarse como base para realizar futuros análisis y mejoras similares en otros centros, teniendo en cuenta la metodología seguida y los cuestionarios realizados.

El artículo se organiza del siguiente modo. En la sección dos se revisa la literatura relacionada con los ODS y el papel clave que juega la educación para su consecución. En la sección tres se explica la metodología seguida para la obtención de los datos necesarios y el análisis de la información obtenida. En la sección cuatro se muestran los resultados obtenidos clasificados en resultados de la dirección, resultados de los profesores y resultados de los alumnos. En la sección cinco, tras analizar la situación en la que se encuentra el centro y la actividad que actualmente realiza en vías de la sostenibilidad, se realiza una propuesta de mejora. Finalmente, en la sección seis se muestran las conclusiones del trabajo.

\section{Revisión de la literatura Objetivos para el Desarrollo Sostenible}

Los ODS son un conjunto de 17 objetivos y 169 metas destinados a resolver los problemas sociales, económicos y ambientales que afectan al mundo para el 2030. Su finalidad es garantizar una vida sostenible, pacífica, próspera y justa en la tierra para todos y todas, ahora y en el futuro. Tal y como explica la Unesco (2017): 
Los objetivos abordan desafíos mundiales cruciales para la supervivencia de la humanidad; fijan los límites ambientales y los umbrales críticos para el uso de recursos naturales; y reconocen que la erradicación de la pobreza debe ir a la par de estrategias que fomenten el desarrollo económico (p. 6).

Se aplican en los siguientes ámbitos: educación, salud, protección social y oportunidades laborales, cambio climático y protección del medioambiente. No se trata de objetivos independientes, sino que se interrelacionan entre sí y suponen el plan maestro para conseguir un futuro sostenible para todos y todas.

Los ODS no son jurídicamente obligatorios. No obstante, se espera que los gobiernos los adopten como propios y establezcan marcos, políticas y medidas a nivel nacional para su implementación y análisis del grado de consecución. Pero no solo se espera la implicación de los gobiernos, sino la de todos y todas: el sector privado, la sociedad civil y todo ser humano (Unesco, 2017). En la tabla 1 se recogen los 17 ODS.

Tabla 1. Los 17 ODS

1) Fin de la pobreza. Poner fin a la pobreza en todas sus formas en todo el mundo.

2) Hambre cero. Poner fin al hambre, lograr la seguridad alimentaria y la mejora de la nutrición y promover la agricultura sostenible.

3) Salud y bienestar. Garantizar una vida sana y promover el bienestar para todos en todas las edades.

4) Educación de calidad. Garantizar una educación inclusiva, equitativa y de calidad y promover oportunidades de aprendizaje durante toda la vida para todos.

5) Igualdad de género. Lograr la igualdad entre los géneros y empoderar a todas las mujeres y las niñas.

6) Agua limpia y saneamiento.

Garantizar la disponibilidad de agua y su gestión sostenible y el saneamiento para todos.

7) Energía asequible y no contaminante. Garantizar el acceso a una
10) Reducción de las desigualdades. Reducir la desigualdad en y entre los países.

11) Ciudades y comunidades sostenibles. Lograr que las ciudades y los asentamientos humanos sean inclusivos, seguros, resilientes y sostenibles.

12) Producción y consumo responsables. Garantizar modalidades de consumo y producción sostenibles.

13) Acción por el clima. Adoptar medidas urgentes para combatir el cambio climático

14) Vida submarina. Conservar $y$ utilizar en forma sostenible los océanos, los mares y los recursos marinos para el desarrollo sostenible

15) Vida de ecosistemas terrestres. Proteger, restablecer y promover el uso sostenible de los ecosistemas terrestres, gestionar sosteniblemente los bosques, luchar contra la desertificación, detener e invertir la degradación de las tierras y detener la pérdida de biodiversidad 
energía asequible, segura, sostenible y moderna para todos.

8) Trabajo decente y crecimiento económico. Promover el crecimiento económico sostenido, inclusivo y sostenible, el empleo pleno y productivo y el trabajo decente para todos

9) Industria, innovación e infraestructura. Consumir infraestructuras resilientes, promover la industrialización inclusiva y sostenible y fomentar la innovación.
16) Paz, justicia e instituciones sólidas. Promover sociedades justas, pacíficas e inclusivas para el desarrollo sostenible, proporcionar a todas las personas acceso a la justicia y desarrollar instituciones eficaces, responsables e inclusivas en todos los niveles

17) Alianzas para lograr objetivos. Fortalecer los medios de ejecución y revitalizar la Alianza Mundial para el Desarrollo Sostenible.

Fuente: Unesco (2017)

Los ODS se encuentran en el centro de la Agenda 2030 para el Desarrollo Sostenible. Este plan de acción mundial tiene como finalidad asegurar un progreso social y económico sostenible en todo el mundo y fortalecer la paz universal.

Esta agenda fue adoptada el 25 de septiembre de 2015 por la Asamblea General de las Naciones Unidas y se puso en marcha el 1 de enero del 2016. Fue creada tras la Conferencia de las Naciones Unidas sobre el Desarrollo Sostenible (Río+20) en Río de Janeiro (Brasil) en el 2012. En su creación participaron todos los estados miembros de la Organización de las Naciones Unidas (ONU) y millones de personas y actores de todo el mundo a través de los estudios nacionales realizados (ONU, 21 de octubre de 2015).

La característica principal de la Agenda 2030 para el Desarrollo, y que la distingue de su antecesora, la Declaración del Milenio, es su universalidad e indivisibilidad (ONU, 21 de octubre de 2015). En la Declaración del Milenio (2000) se promulgaron los ocho Objetivos de Desarrollo del Milenio (ODM), los cuales estaban centrados en los países menos desarrollados. Los ODS, sin embargo, están planteados para todos los países del mundo, ya que son universales, transformadores e inclusivos. Su objetivo es ampliar los avances logrados por sus antecesores y cumplir con aquellos puntos que no fueron alcanzados (Unesco, 2017). 


\section{El doble papel de la educación: ODS a alcanzar y medio para alcanzar el resto de los ODS}

\section{La educación y la Unesco}

La Unesco fue fundada el 16 de noviembre de 1945 con el ambicioso objetivo de contribuir a la paz y la seguridad en el mundo mediante la educación, la ciencia, la cultura y las comunicaciones (Unesco, 2019). A lo largo de la historia, junto con otros factores como el económico, la educación ha mostrado ser un pilar fundamental en el desarrollo sostenible. Así, desde 1992, la Unesco (Unesco, 1992) ha promovido la educación para el desarrollo sostenible (EDS).

La educación es la prioridad principal de la Unesco, ya que es un derecho humano esencial, a la vez que la base para consolidar la paz e impulsar el desarrollo sostenible. Irene Bokova, directora general de la Unesco del 2009 al 2017, afirma lo siguiente en el prólogo de Replantear la educación: ¿Hacia un bien común mundial? (Unesco, 2015a):

No existe una forma transformadora más poderosa que la educación para promover los derechos humanos y la dignidad, erradicar la pobreza y lograr la sostenibilidad, construir un futuro mejor para todos, basado en la igualdad de derechos y la justicia social, el respeto de la diversidad cultural, la solidaridad internacional y la responsabilidad compartida, aspiraciones que constituyen aspectos fundamentales de nuestra humanidad común (p. 4).

\section{Educación para el desarrollo sostenible}

La educación es en sí misma uno de los ODS: el cuarto. Se trata de garantizar una educación inclusiva, equitativa y de calidad y promover oportunidades de aprendizaje durante toda la vida para todos. Dentro de este objetivo, se plantean siete metas; la séptima es la que está relacionada con los objetivos de este trabajo:

4.7 De aquí al 2030 asegurar que todos los alumnos y alumnas adquieran los conocimientos teóricos y prácticos necesarios para promover el desarrollo sostenible, entre otras cosas mediante la educación para el desarrollo sostenible y los estilos de vida sostenibles, los derechos humanos, la igualdad de género, la promoción de una cultura de paz y no violencia, la ciudadanía mundial y la valoración de la diversidad cultural y la contribución de la cultura al Desarrollo Sostenible (Unesco, 2015b, p. 73). 


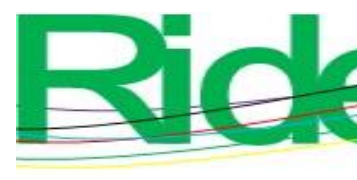

Revista Iberoamericana para la Investigación y el Desarrollo Educativo ISSN 2007 - 7467

Es debido a esta meta que la educación tiene un doble papel: el de objetivo a ser logrado y el de estrategia esencial para alcanzar el resto de los ODS. En palabras de Quian Tang (citado en Unesco, 2017), subdirector general de Educación de la Unesco:

Temas mundiales —como el cambio climático- requieren de forma urgente un cambio en nuestros estilos de vida y una transformación en nuestra forma de actuar y pensar. Para lograrlo, necesitamos nuevas competencias, actitudes y conductas que nos conduzcan a sociedades más sostenibles (p. 1).

Estos conocimientos, habilidades, valores y actitudes necesarios para fomentar el desarrollo sostenible son trabajados mediante la EDS.

La EDS apunta a desarrollar competencias que empoderen a los individuos para reflexionar sobre sus propias acciones, tomando en cuenta sus efectos sociales, culturales, económicos y ambientales actuales y futuros. Esto lo realiza desde una doble perspectiva, local y mundial, para actuar en situaciones complejas de una manera sostenible, aún si esto requiriera aventurarse en nuevas direcciones; y para participar en los procesos sociopolíticos a fin de impulsar a las sociedades hacia un desarrollo sostenible (Unesco, 2017). A través de la EDS, el alumnado adquiere competencias clave para la sostenibilidad que son relevantes para todos los ODS y unos resultados específicos para cada uno de ellos.

Las ocho competencias transversales clave para la sostenibilidad y sus definiciones son las siguientes (Unesco, 2017):

1) Competencia de pensamiento sistemático: se refiere a las habilidades para reconocer y comprender las relaciones; para analizar los sistemas complejos; para pensar cómo están integrados los sistemas dentro de los distintos dominios y escalas, y para lidiar con la incertidumbre.

2) Competencia de anticipación: se refiere a las habilidades para comprender y evaluar múltiples escenarios futuros, el posible, el probable y el deseable; para crear visiones propias de futuro; para aplicar el principio de precaución; para evaluar las consecuencias de las acciones, y para lidiar con los riesgos y los cambios.

3) Competencia normativa: Se refiere a las habilidades para comprender y reflexionar sobre las normas y valores que subyacen en nuestras acciones, y para negociar los valores, principios, objetivos y metas de sostenibilidad en un contexto de conflictos, de intereses y concesiones mutuas, conocimiento incierto y contradicciones. 
4) Competencia estratégica: se refiere a las habilidades para desarrollar e implementar de forma colectiva acciones innovadoras que fomenten la sostenibilidad a nivel local y más allá.

5) Competencia de colaboración: se refiere a las habilidades para aprender de otros; para comprender y respetar las necesidades, perspectivas y acciones de otros (empatía); para comprender, identificarse y ser sensibles con otros (liderazgo empático); para abordar conflictos en grupo, y para facilitar la resolución de problemas colaborativa y participativamente.

6) Competencia de pensamiento crítico: se refiere a la habilidad para cuestionar normas, prácticas y opiniones; para reflexionar sobre los valores, percepciones y acciones propias, y para adoptar una postura en el discurso de la sostenibilidad.

7) Competencia de autoconciencia: se refiere a la habilidad para reflexionar sobre el rol que cada uno tiene en la comunidad local y en la sociedad (mundial); de evaluar de forma constante e impulsar las acciones que uno mismo realiza, y de lidiar con los sentimientos y deseos personales.

8) Competencia integrada de resolución de problemas: se refiere a la habilidad general para aplicar distintos marcos de resolución de problemas de sostenibilidad complejos e idear opciones de solución equitativa que fomenten el desarrollo sostenible, integrando las competencias antes mencionadas.

Estas competencias son relevantes para todos los ODS, pero también permiten a los individuos vincular los distintos ODS entre sí, con el fin de tener una visión global de la Agenda 2030 para el Desarrollo Sostenible (Unesco, 2017).

\section{Metodología}

La metodología de investigación seguida para analizar el involucramiento de un instituto de educación secundaria en la EDS, tanto en las diferentes asignaturas como a nivel de centro mediante los diferentes proyectos que se llevan a cabo, fue la siguiente (figura 1).

En primer lugar, se revisó la literatura relacionada con los ODS y la EDS, lo que permitió determinar la información que se quería obtener de cada una de las fuentes (dirección, profesorado y alumnado). 
Figura 1. Metodología

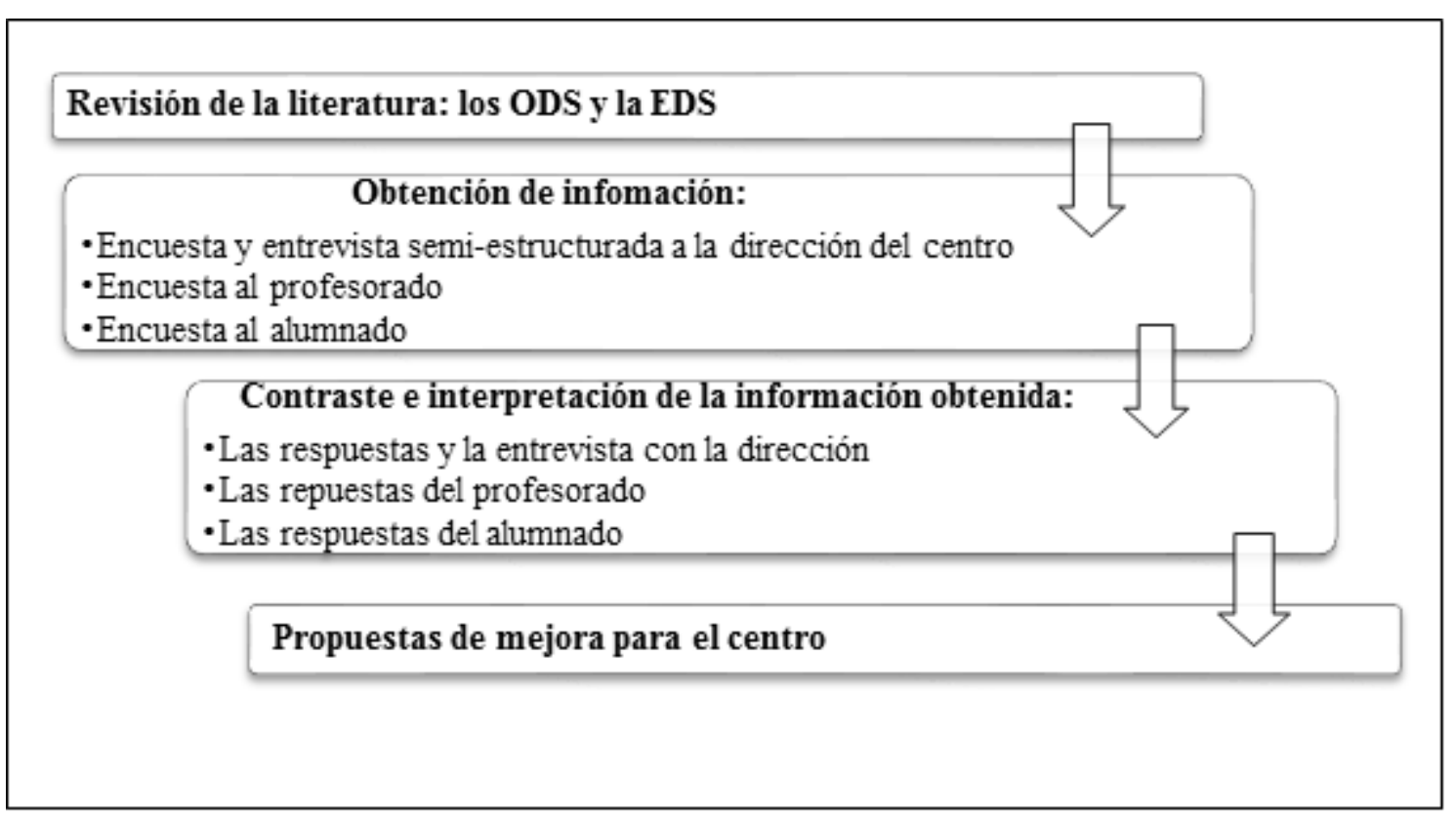

Fuente: Elaboración propia

A continuación, se elaboraron tres cuestionarios para obtener información de tres fuentes distintas: la dirección del centro, los docentes, y los alumnos (en los anexos 1, 2, y 3 se muestran los tres cuestionarios). La encuesta a la dirección y a los alumnos se realizó en papel (los encuestadores estuvieron presentes). La encuesta a los profesores se realizó online. A la dirección del centro se le realizó también una entrevista semiestructurada mediante la cual se obtuvo información general sobre el centro, su participación en programas externos, la opinión de la dirección sobre los ODS y la EDS, y se obtuvo una visión global de los proyectos a nivel de centro que estaban en marcha. Para la realización de los cuestionarios, se revisó la literatura existente sobre la elaboración de cuestionarios; se identificaron qué tipo de cuestionarios existen (Díaz, 2019) y las ventajas y desventajas de cada uno de ellos (OpenCourseWare, 2017). Para la definición de qué estructura debían seguir los cuestionarios, qué preguntas realizar, qué lenguaje utilizar, el aspecto formal del cuestionario, cómo llegar al público objetivo y cómo interpretar los resultados obtenidos, se han tenido en cuenta los manuales de dos de las principales plataformas online para la elaboración de encuestas: Typeform (2019) y SurveyMonkey (2019). La tabla 2 muestra para cada uno de los tres cuestionarios elaborados la información que se deseaba obtener, el tipo de cuestionario, el tipo de preguntas, la estructura del cuestionario y la población del estudio.

Tras la obtención de información se contrastaron e interpretaron los resultados obtenidos, y se realizaron las propuestas de mejora para el centro. 
Tabla 2. Características de los cuestionarios realizados

\begin{tabular}{|c|c|c|c|}
\hline & $\begin{array}{l}\text { Cuestionario para la } \\
\text { dirección (anexo 1) }\end{array}$ & $\begin{array}{l}\text { Cuestionario para } \\
\text { el profesorado } \\
\text { (anexo 2) }\end{array}$ & $\begin{array}{l}\text { Cuestionario para } \\
\text { el alumnado (anexo } \\
\text { 3) }\end{array}$ \\
\hline $\begin{array}{l}\text { Información por } \\
\text { obtener }\end{array}$ & $\begin{array}{l}\text { - Conocimiento de la } \\
\text { dirección sobre los } \\
\text { ODS y la EDS. } \\
\text { - Opinión de la } \\
\text { dirección sobre la } \\
\text { importancia de la } \\
\text { EDS y la formación } \\
\text { del profesorado. } \\
\text { - Conocer los } \\
\text { proyectos y } \\
\text { programas a nivel } \\
\text { del centro } \\
\text { relacionados con los } \\
\text { ODS. }\end{array}$ & $\begin{array}{l}\text { - Conocimiento, } \\
\text { fuente de este e } \\
\text { interés del } \\
\text { profesorado sobre } \\
\text { los ODS y la EDS. } \\
\text { - Cómo cada } \\
\text { profesor colabora en } \\
\text { la EDS tratando } \\
\text { temas relacionados } \\
\text { con los ODS y } \\
\text { contribuyendo a la } \\
\text { adquisición por parte } \\
\text { del alumnado de las } \\
\text { competencias clave } \\
\text { para el desarrollo } \\
\text { sostenible mediante } \\
\text { su asignatura. } \\
\text { - Conocimiento y } \\
\text { valoración del } \\
\text { profesorado sobre } \\
\text { las acciones de } \\
\text { sostenibilidad del } \\
\text { centro. }\end{array}$ & $\begin{array}{l}\text { - Qué ODS perciben } \\
\text { que se imparten en el } \\
\text { centro. } \\
\text { - Cómo valora el } \\
\text { alumnado los } \\
\text { diferentes proyectos } \\
\text { realizados en el } \\
\text { centro relacionados } \\
\text { con los ODS. } \\
\text { - Mediante qué } \\
\text { asignaturas y en qué } \\
\text { grado creen que se } \\
\text { profundizan estos } \\
\text { temas. } \\
\text { - Qué temas } \\
\text { relacionados con los } \\
\text { ODS les gustaría que } \\
\text { se profundizasen en } \\
\text { el centro. }\end{array}$ \\
\hline Tipo de cuestionario & $\begin{array}{l}\text { 1. }{ }^{\text {a }} \text { parte: encuesta } \\
\text { estructurada, } \\
\text { descriptiva y en } \\
\text { papel. } \\
2 .^{\text {a }} \text { parte: } \\
\text { cuestionario } \\
\text { semiestructurado, } \\
\text { exploratorio, } \\
\text { entrevista. }\end{array}$ & $\begin{array}{l}\text { Descriptivo, } \\
\text { estructurado y online }\end{array}$ & $\begin{array}{l}\text { Descriptivo, } \\
\text { estructurado y en } \\
\text { papel }\end{array}$ \\
\hline Tipo de preguntas & $\begin{array}{l}\text { Dos partes: } \\
\text { 1. }{ }^{\text {a }} \text { parte: preguntas } \\
\text { cerradas de escala } \\
\text { Likert, preguntas } \\
\text { abiertas } \\
\text { 2. }{ }^{\text {a }} \text { parte: preguntas } \\
\text { abiertas }\end{array}$ & $\begin{array}{l}\text { - Preguntas cerradas: } \\
\text { dicotómicas, de } \\
\text { escala Likert y de } \\
\text { múltiple elección. } \\
\text { - Preguntas abiertas: } \\
\text { utilizadas para } \\
\text { completar las }\end{array}$ & $\begin{array}{l}\text { - Preguntas cerradas: } \\
\text { dicotómicas, de } \\
\text { escala Likert y de } \\
\text { elección múltiple. } \\
\text { - Preguntas abiertas: } \\
\text { utilizadas para } \\
\text { completar las }\end{array}$ \\
\hline
\end{tabular}




\begin{tabular}{|c|c|c|c|c|}
\hline & & $\begin{array}{l}\text { respuestas cerradas } \\
\text { anteriores. } \\
\text { - Preguntas mixtas. }\end{array}$ & $\begin{array}{l}\text { respuestas cerradas } \\
\text { anteriores. } \\
\text { - Preguntas mixtas. }\end{array}$ \\
\hline \multirow{4}{*}{ 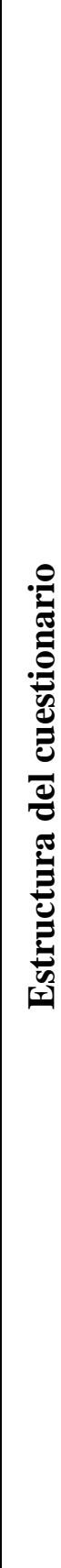 } & $\begin{array}{l}\text { 1) } \\
\text { Presentación } \\
\text { y } \\
\text { justificación } \\
\text { del estudio }\end{array}$ & \multicolumn{3}{|c|}{ Explicación del objetivo del estudio } \\
\hline & $\begin{array}{l}\text { 2) Preguntas } \\
\text { introductorias }\end{array}$ & $\begin{array}{l}\text { Cargo en el centro, } \\
\text { años en la docencia, } \\
\text { en el centro y en el } \\
\text { cargo. }\end{array}$ & $\begin{array}{l}\text { - Funcionario o } \\
\text { interino } \\
\text { - El departamento al } \\
\text { que pertenece } \\
\text { - Años en el centro y } \\
\text { en la docencia }\end{array}$ & $\begin{array}{l}\text { - Curso } \\
\text { - Conocimiento } \\
\text { previo }\end{array}$ \\
\hline & $\begin{array}{l}\text { 3) Preguntas } \\
\text { clave }\end{array}$ & $\begin{array}{l}\text { 1) Conocimiento de } \\
\text { los ODS y la EDS } \\
\text { 2) Interés personal } \\
\text { sobre los ODS y la } \\
\text { EDS } \\
\text { 3) Formación al } \\
\text { profesorado }\end{array}$ & $\begin{array}{l}\text { 1) Conocimiento } \\
\text { general sobre los } \\
\text { ODS y la EDS. } \\
\text { 2) Valoración del } \\
\text { grado con el que se } \\
\text { trabaja cada uno de } \\
\text { los ODS en su } \\
\text { asignatura y cómo. } \\
\text { 3) Valoración de } \\
\text { cómo ayuda } \\
\text { mediante su } \\
\text { asignatura a la } \\
\text { adquisición de las } \\
\text { competencias clave. } \\
\text { 4) Interés del } \\
\text { profesorado en el } \\
\text { tema. }\end{array}$ & $\begin{array}{l}\text { 1) Preguntas } \\
\text { relacionadas con los } \\
\text { temas que ya } \\
\text { trabajan sobre los } \\
\text { diferentes ODS. } \\
\text { 2) Qué información } \\
\text { les gustaría recibir y } \\
\text { trabajar relacionados } \\
\text { con los ODS. }\end{array}$ \\
\hline & $\begin{array}{l}\text { 4.Agradecimi } \\
\text { ento por la } \\
\text { colaboración }\end{array}$ & Agradeci & iento por la colaborac & n prestada \\
\hline \multicolumn{2}{|c|}{ Población del estudio } & Equipo directivo & Profesorado & Alumnado \\
\hline
\end{tabular}

Fuente: Elaboración propia 


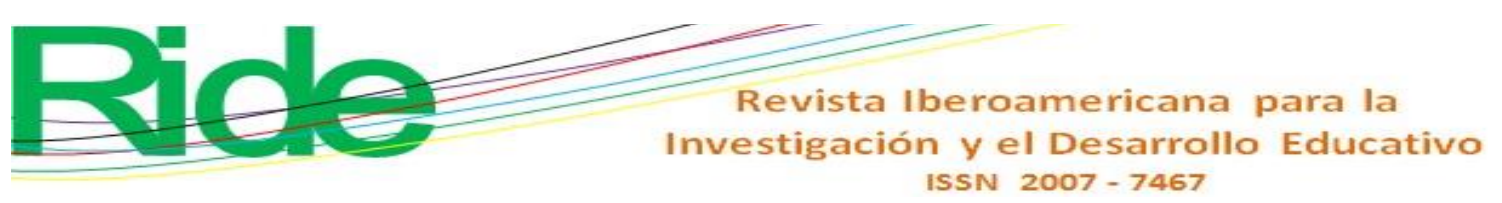

\section{Análisis de los resultados obtenidos}

El centro analizado es el Instituto de Educación Secundaria Iturrama (IES Iturrama). Está situado en el barrio pamplonés de Iturrama. Cuenta con 749 alumnos y alumnas, y es el más grande dentro del modelo educativo D (modalidad en euskera) de la comunidad foral de Navarra. El centro cuenta con 93 docentes, de los cuales solo $40 \%$ es funcionario, mientras que el restante $60 \%$ es interino. Este alto porcentaje hace que cada año el profesorado vaya cambiando, lo cual dificulta la continuidad de los proyectos relacionados con los ODS y la EDS.

\section{Resultados de la dirección}

Del cuestionario y la entrevista con la dirección se concluye que el centro está llevando a cabo cuatro acciones relacionadas con los ODS y la EDS: los proyectos Iturrama Solidario e Iturrama Verde, el programa Skolae y la formación del profesorado en la metodología cooperar para aprender / aprender a cooperar (CA/AC). A continuación, se explican cada una de dichas acciones.

\section{Iturrama Solidario}

Iturrama Solidario es un proyecto que se lleva a cabo principalmente en la asignatura de Ciencias Sociales de 3. ${ }^{\circ}$ de la Educación Secundaria Obligatoria (ESO), aunque hay actividades realizadas en otros cursos y asignaturas. El objetivo es dar a conocer lo trabajado en clase en relación con la situación actual del Sahara a toda la comunidad educativa. El trabajo realizado por el alumnado sobre el Sáhara se presenta al resto del centro en la semana cultural mediante diferentes actividades, tales como decorar el centro con motivos saharauis, charlas con testigos o personas cooperantes, recogida de ropa, etc.

\section{Iturrama Verde}

Iturrama Verde es un proyecto cuyo objetivo es inculcar costumbres sostenibles al alumnado mediante diferentes actividades, por ejemplo, huertas urbanas, actividades relacionadas con el reciclaje, con el uso del agua, etc. Iturrama Verde es competencia del Departamento de Ciencias Naturales y se realiza en $1 .^{\circ}$ de la ESO.

En la tabla 3 se muestra el número de años que ambos proyectos llevan en marcha, el departamento encargado del proyecto, el resto de los departamentos implicados, los 
ODS tratados, las competencias obtenidas por el alumnado y la nota de satisfacción que le dan los alumnos a ambos proyectos.

Tabla 3. Comparativa de los proyectos Iturrama Solidario e Iturrama Verde

\begin{tabular}{|c|c|c|}
\hline Red en la que se participa & $\begin{array}{c}\text { Iturrama Solidario } \\
\text { Red de Escuelas Solidarias } \\
\text { de Navarra }\end{array}$ & $\begin{array}{c}\text { Red de Escuelas } \\
\text { Sostenibles de Navarra }\end{array}$ \\
\hline $\begin{array}{c}\text { Cursos que lleva en } \\
\text { marcha }\end{array}$ & 5 & 4 \\
\hline $\begin{array}{c}\text { Departamento encargado } \\
\text { Resto de departamentos } \\
\text { implicados }\end{array}$ & Ciencias Sociales $^{\text {Matemática, Religión }}$ & $\begin{array}{c}\text { Biología (Ciencias } \\
\text { Naturales) }\end{array}$ \\
\hline $\begin{array}{c}\text { Competencias para la } \\
\text { sostenibilidad }\end{array}$ & $\begin{array}{c}\text { Todemática, Filosofía, } \\
\text { Tecnología }\end{array}$ \\
\hline Curso principal & $3 .^{\circ}$ ESO & Todas \\
\hline ODS tratados & $1,2,3,4,5,6,7,8,9,10,11$, & $4,6,7,8,9,10,11,12,13$, \\
$12,16,17$ & 6,15 \\
\hline Nota del alumnado & 7,61 & 6,75 \\
\hline
\end{tabular}

Fuente: Elaboración propia

Un aspecto para destacar en relación con los proyectos que se llevan a cabo en el centro es que los ODS no son tenidos en cuenta a la hora de valorar la puesta en marcha de un nuevo proyecto, aunque sí se tienen en cuenta los proyectos propuestos por los departamentos y las inquietudes del alumnado.

\section{Skolae}

Skolae es un programa de coeducación creado por el Gobierno de Navarra y premiado por la Unesco en 2019. Al respecto:

El itinerario sirve para la adquisición progresiva de las competencias básicas que permitirán a las niñas y a los niños elegir, construir y vivir el proyecto vital propio desde el conocimiento, la libertad y la capacidad de decidir sobre su futuro sin condicionantes de género, aprendiendo a identificar las desigualdades, a luchar contra ellas y a ejercer su derecho a la igualdad en el ámbito de su cultura, religión, clase social, situación funcional, etc. (Gobierno de Navarra, 2017, p. 12).

Por lo tanto, mediante este programa se trabaja de manera directa el ODS 5 relativo a la igualdad de género. 


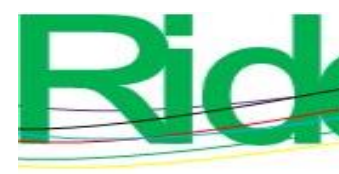

Se trata de un programa transversal, por lo que se aplica a todas las áreas de conocimiento y se considera en todos los aspectos docentes (objetivos de las asignaturas, contenidos, competencias básicas y criterios de evaluación). Skolae se puso en marcha en el curso 2017/2018 en diferentes centros piloto; el IES Iturrama fue uno de ellos. Las actividades de Skolae se realizan sobre todo mediante las horas de tutoría, aunque también se realizan actividades concretas en distintas asignaturas, pero de manera puntual. Además, dentro de la puesta en marcha del programa Skolae, se han realizado diversas acciones al margen de las docentes: convertir los baños en mixtos en vez de separarlos por sexo o la creación de un grupo feminista formado por alumnas y alumnos del centro que se encarga de organizar las actividades a favor del feminismo.

El profesorado valora el programa con un 7.95 sobre 10. Aunque todo el profesorado conoce el programa, $36.36 \%$ admite no conocerlo a fondo y no saber exactamente cómo llevarlo a cabo, ya que, aunque los docentes que han recibido la formación dicen que ha sido muy productiva, no todo el profesorado la ha recibido. No obstante, en todas las asignaturas se trabaja el objetivo de igualdad de género de manera transversal, por ejemplo, mediante el uso de lenguaje inclusivo, lo que da visibilidad a todas las desigualdades existentes, y comentando textos, documentales y libros sobre el feminismo, etc. Así, el ODS 5 de igualdad de género es el más trabajado en el instituto y en todas las asignaturas.

Respecto a los alumnos, como se ve en la figura 2, $42 \%$ del alumnado opina que las actividades realizadas en el centro son adecuadas pero que falta bastante por hacer para lograr la igualdad efectiva. Los comentarios más repetidos en la valoración son los siguientes: "se realizan muchas actividades, pero aún queda mucho por hacer", "mejor que en otros centros, pero demasiada teoría y sigue habiendo diferencias" y "buen trabajo del grupo feminista". 
Figura 2. Valoración de las actividades encaminadas a la igualdad de sexo por los alumnos

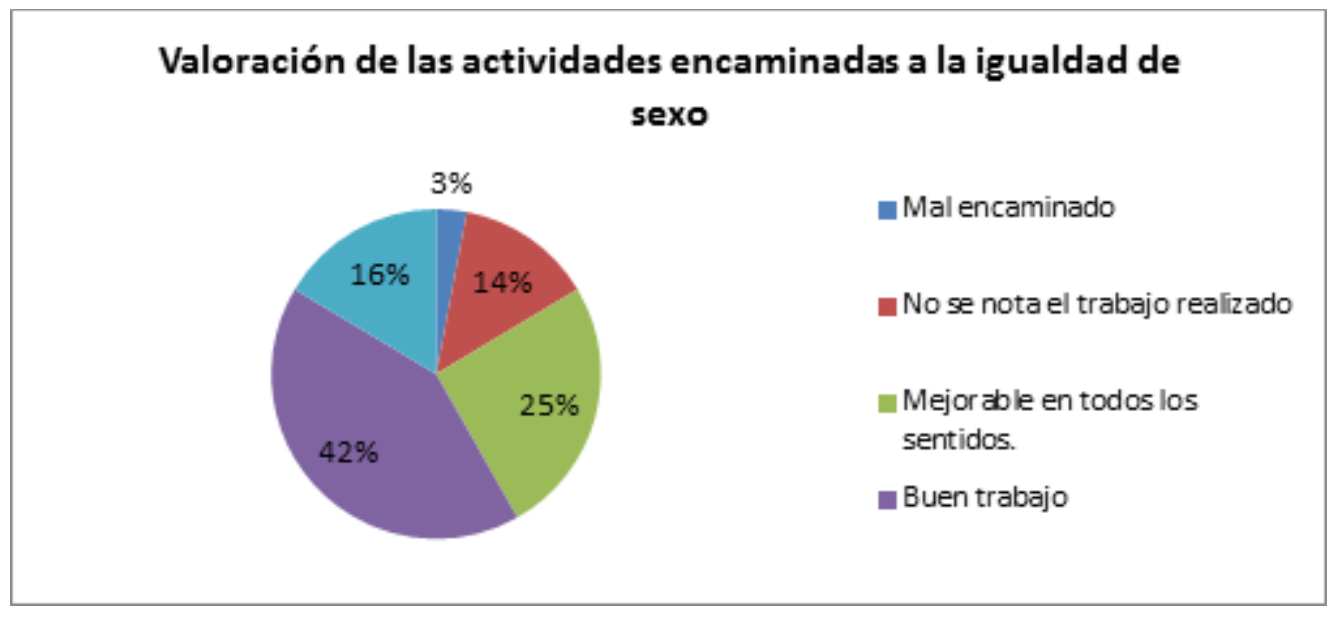

Fuente: Elaboración propia

\section{Metodología cooperar para aprender / aprender a cooperar}

Esta metodología está compuesta de un conjunto de actuaciones encaminadas a enseñar al alumnado a trabajar en equipo, que es la manera más adecuada de enseñar de modo inclusivo y teniendo en cuenta la diversidad del alumnado. Se trata de una metodología con tres pilares fundamentales: la enseñanza personalizada, la autonomía de los estudiantes y la estructura cooperativa del aprendizaje (Pujolàs y Lago, 2012). Está totalmente vinculada con la competencia clave para la sostenibilidad, la colaboración. Desde hace dos cursos se está formando al profesorado para poder aplicar esta metodología en todos los cursos y asignaturas.

Para la correcta consecución de las cuatro acciones anteriormente mencionadas afecta mucho el alto grado de interinidad que hay en el centro (57\% del profesorado), ya que cada año hay nuevo equipo docente y requiere de una formación continua para que las acciones puedan implementarse correctamente.

\section{Resultados de los profesores}

\section{Conocimiento e interés del profesorado en los ODS y la EDS}

Del equipo docente del centro, $53.76 \%$ participó en la encuesta (68 \% interino y $32 \%$ funcionario). En la figura 3 se puede ver la participación por departamentos. 
Figura 3. Participación del profesorado en la encuesta por departamentos

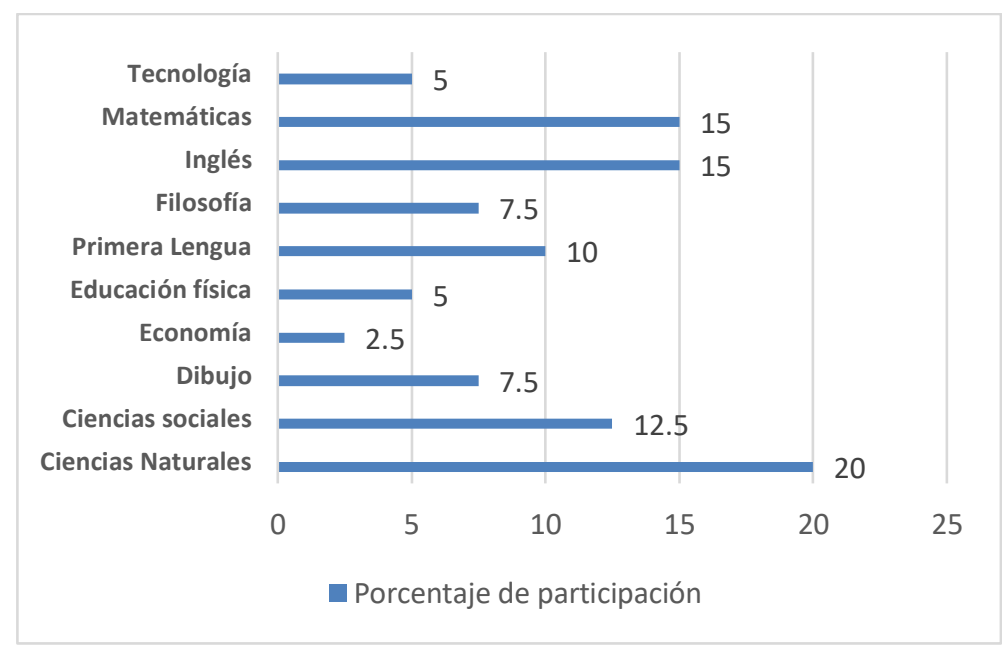

Fuente: Elaboración propia

Solo $6.68 \%$ del profesorado que participó en la encuesta ha recibido algún tipo de formación relacionada con la sostenibilidad. En concreto, un máster en sostenibilidad, un máster medioambiental, la formación para monitor medioambiental y la participación en formaciones impartidas por la Red de Escuelas Solidarias de Navarra.

Al preguntar sobre el conocimiento previo sobre los ODS y la EDS, se puede observar que la mayoría del profesorado participante considera tener un conocimiento previo medio sobre los ODS. Sin embargo, el conocimiento es mayor en la EDS, ya que $38 \%$ considera tener un conocimiento completo (total) sobre la EDS (figura 4).

Figura 4. Conocimiento del profesorado sobre los ODS y la EDS

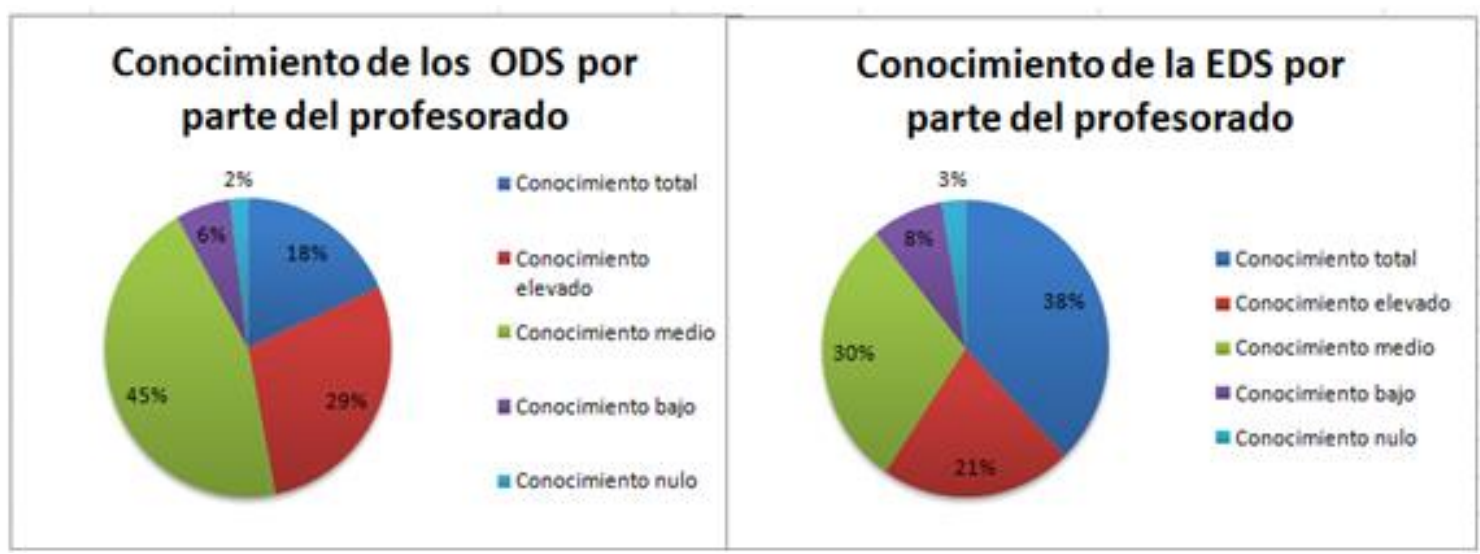

Fuente: Elaboración propia

En cuanto al análisis por departamentos, se puede observar que el conocimiento medio sobre los ODS es de 3.25 sobre 10; por encima de la media se encuentran los departamentos de Ciencia Sociales, Filosofía, Primera Lengua y Economía (figura 5). Sin embargo, solo el Departamento de Economía tiene un conocimiento pleno de los ODS; 
los demás están por debajo del cinco. La media sobre el conocimiento de la EDS es de 5.33; por encima de la media están los departamentos de Naturales, Primera Lengua, Filosofía y Economía. En ninguno de los casos hay diferencia entre interinos y funcionarios. Para comprobar que la nota que cada docente ponía a su propio conocimiento era correcta, se les pidió que hicieran un breve resumen de cada concepto, lo que permitió comprobar la veracidad de sus respuestas.

Figura 5. Conocimiento del profesorado de los ODS y la EDS por departamentos

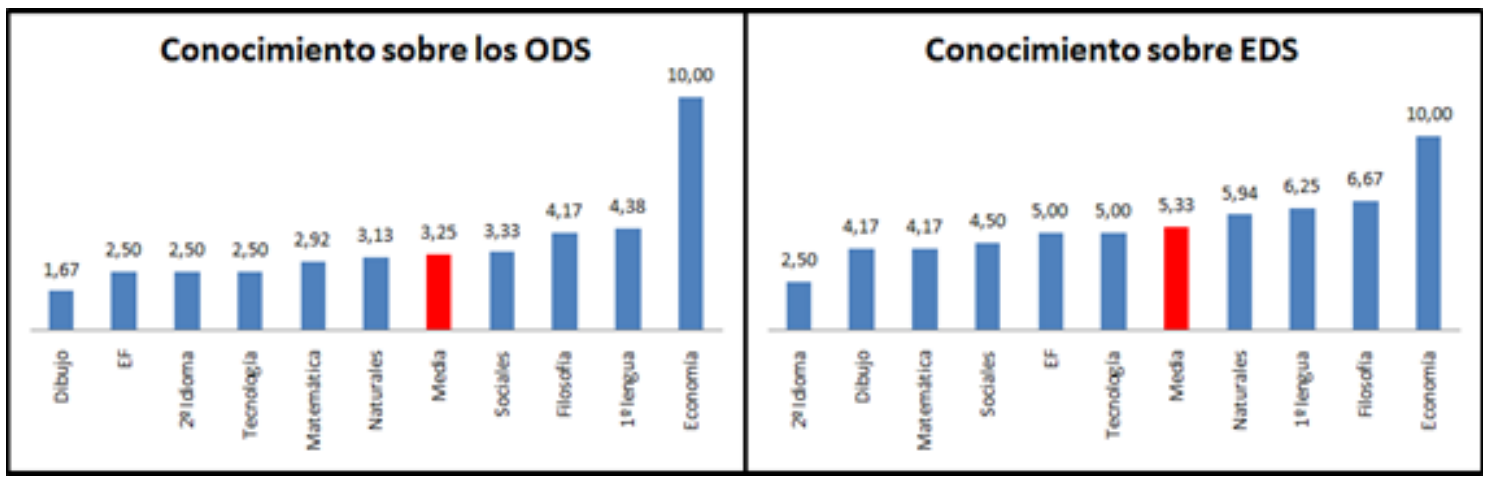

Fuente: Elaboración propia

Sobre la necesidad de formación del profesorado en temas de sostenibilidad, $84 \%$ del profesorado participante opina que es de gran importancia (suma de importancia Relevante e Imprescindible) la formación del profesorado en temas de sostenibilidad (figura 6). Esta respuesta va acorde con la respuesta de la dirección, que también opina que es de gran importancia formar al profesorado en sostenibilidad.

Sobre el tipo de formación relacionada con el tema que estarían dispuestos a recibir, la condición más repetida por parte del profesorado para recibir un curso sobre el tema es que se trate de un curso gratuito. En cuanto a modalidad, $66.67 \%$ de los interesados preferirían que fuera online, mientras que $33.33 \%$ presencial. Cabe destacar que, aunque muchos muestren interés, teniendo en cuenta el grado de interinidad del centro, solo estarían dispuestos a recibir esta formación si fuera obligatorio o diera puntos para un futuro concurso de oposición. Una sugerencia relevante es la importancia de centrar el curso en cada asignatura para obtener herramientas e ideas concretas sobre cómo tratar los diferentes ODS y competencias en cada asignatura de forma específica y que no sea un curso meramente teórico. 
Figura 6. Importancia sobre la formación del profesorado en temas de sostenibilidad

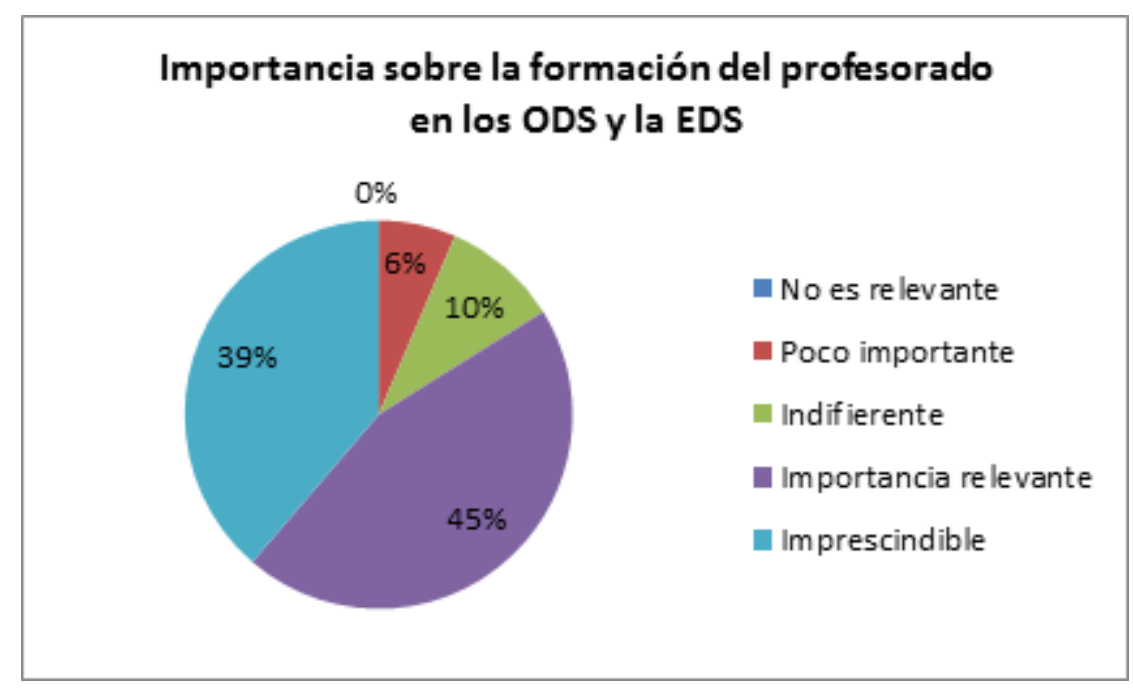

Fuente: Elaboración propia

\section{Objetivos trabajados mediante las asignaturas}

A partir de los cuestionarios realizados a los profesores, se ha podido determinar los ODS que se consideran en cada asignatura, según su punto de vista. En la tabla 4 se muestra las medias sobre 10 de cómo el profesorado de cada área de asignaturas considera que trabaja los 17 ODS en su asignatura. Para que la interpretación sea más gráfica, se ha clasificado por colores: verde fuerte: $8-10 \rightarrow$ Gran profundidad; verde claro: 6-8 $\rightarrow$

Profundidad elevada; amarillo: 4-6 $\rightarrow$ Profundidad media; naranja: 2-4 $\rightarrow$ Profundidad baja, y rojo: $0-2 \rightarrow$ No se menciona. 
Tabla 4. Objetivos trabajados por asignaturas

\begin{tabular}{|c|c|c|c|c|c|c|c|c|c|c|c|c|c|c|c|c|c|}
\hline & $\underset{\sim}{\bigoplus}$ & $\underset{\sim}{\bigoplus}$ & $\underset{\sim}{\bigoplus}$ & $\underset{\sim}{\ominus}$ & 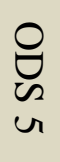 & 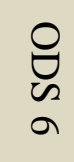 & $\underset{\sim}{\vartheta}$ & 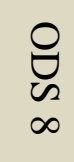 & $\underset{\sim}{\bigoplus}$ & 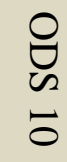 & $\begin{array}{l}\ominus \\
\varpi \\
\rightleftharpoons\end{array}$ & $\begin{array}{l}\vartheta \\
\mathscr{\sim} \\
\tilde{N}\end{array}$ & $\underset{\sim}{\underset{\omega}{\omega}}$ & $\begin{array}{l}\ominus \\
\underset{\sim}{\Delta} \\
\vec{D}\end{array}$ & $\begin{array}{l}\vartheta \\
\stackrel{\vartheta}{\sim} \\
\dot{u}\end{array}$ & $\begin{array}{l}\vartheta \\
\underset{\sim}{0} \\
\vec{a}\end{array}$ & 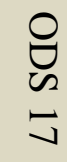 \\
\hline $\begin{array}{l}\text { Ciencias } \\
\text { Naturales }\end{array}$ & 5 & 4 & 9 & 9 & 10 & 7.5 & 8.5 & 3.5 & 5.5 & 6.5 & 6.5 & 7.5 & 8.5 & 5.5 & 7.5 & 6 & 5 \\
\hline $\begin{array}{l}\text { Ciencias } \\
\text { Sociales }\end{array}$ & 8.5 & 8.5 & 3 & 8.5 & $\begin{array}{c}9 . \\
5\end{array}$ & 8 & 8 & 8.5 & 8 & 8.5 & 6.5 & 8.5 & 7 & 3.5 & 2.5 & 9 & 7 \\
\hline Dibujo & 0 & 0 & 2.5 & 6.3 & 10 & 0 & 0 & 0 & 0 & 2.5 & 5 & 6.3 & 6.3 & 6.3 & 6.3 & 7.5 & 7.5 \\
\hline Economía & 7.5 & 7.5 & 5 & 7.5 & 10 & 7.5 & 7.5 & 10 & 7.5 & 10 & 7.5 & 10 & 10 & 2.5 & 5 & 10 & 10 \\
\hline $\begin{array}{c}\text { Educación } \\
\text { Física }\end{array}$ & 0 & 0 & 10 & 3.8 & $\begin{array}{l}8 . \\
8\end{array}$ & 0 & 0 & 0 & 0 & 0 & 8.8 & 0 & 0 & 0 & 0 & 0 & 0 \\
\hline $1^{\circ}$ lengua & 5 & 5 & 6.9 & 6.3 & 8. & 5 & 5 & 6.3 & 1.3 & 6.3 & 1.3 & 6,9 & 6.3 & 2.5 & 2.5 & 6.3 & 6.3 \\
\hline $\begin{array}{c}\text { Física/quím } \\
\text { ica }\end{array}$ & 0 & 0 & 5 & 5 & $\begin{array}{l}7 . \\
5\end{array}$ & 5 & 7.5 & 0 & 1.3 & 6.3 & 0 & 7.5 & 7.5 & 1.3 & 1.3 & 0 & 0 \\
\hline Filosofía & 6.3 & 6.3 & 7.5 & 6.3 & 8. & 2.5 & 6.3 & 1.3 & 2.5 & 7.5 & 5 & 5 & 6.3 & 1.3 & 0 & 8.8 & 8.8 \\
\hline Inglés & 2.5 & 1.3 & 4.4 & 5.6 & 8. & 1.3 & 2.5 & 4.4 & 1.3 & 6.3 & 3.8 & 5 & 3.8 & 1.3 & 1.3 & 6.3 & 3.1 \\
\hline Matemática & 2.9 & 0.8 & 2.1 & 1.7 & 1. & 0 & 0.4 & 0.4 & 0.4 & 0.8 & 0 & 2.5 & 1.3 & 0 & 0 & 0 & 0 \\
\hline Tecnología & 5 & 0 & 5 & 6.3 & 8. & 7.5 & 7.5 & 1.3 & 6.3 & 5 & 8.8 & 8.8 & 8.8 & 1.3 & 1.3 & 1.3 & 1.3 \\
\hline Media & 3.9 & 3 & 5.5 & 6 & 8. & 4 & 4.8 & 3.2 & 3.1 & 5.4 & 4.8 & 6.2 & 6 & 2.3 & 2.5 & 5 & 4.4 \\
\hline
\end{tabular}

\section{Fuente: Elaboración propia}

Por otra parte, en la figura 7 se muestran los ODS que se tratan mediante las tutorías, según el peso de cada uno en estas horas. 
Figura 7. Objetivos trabajados en tutoría

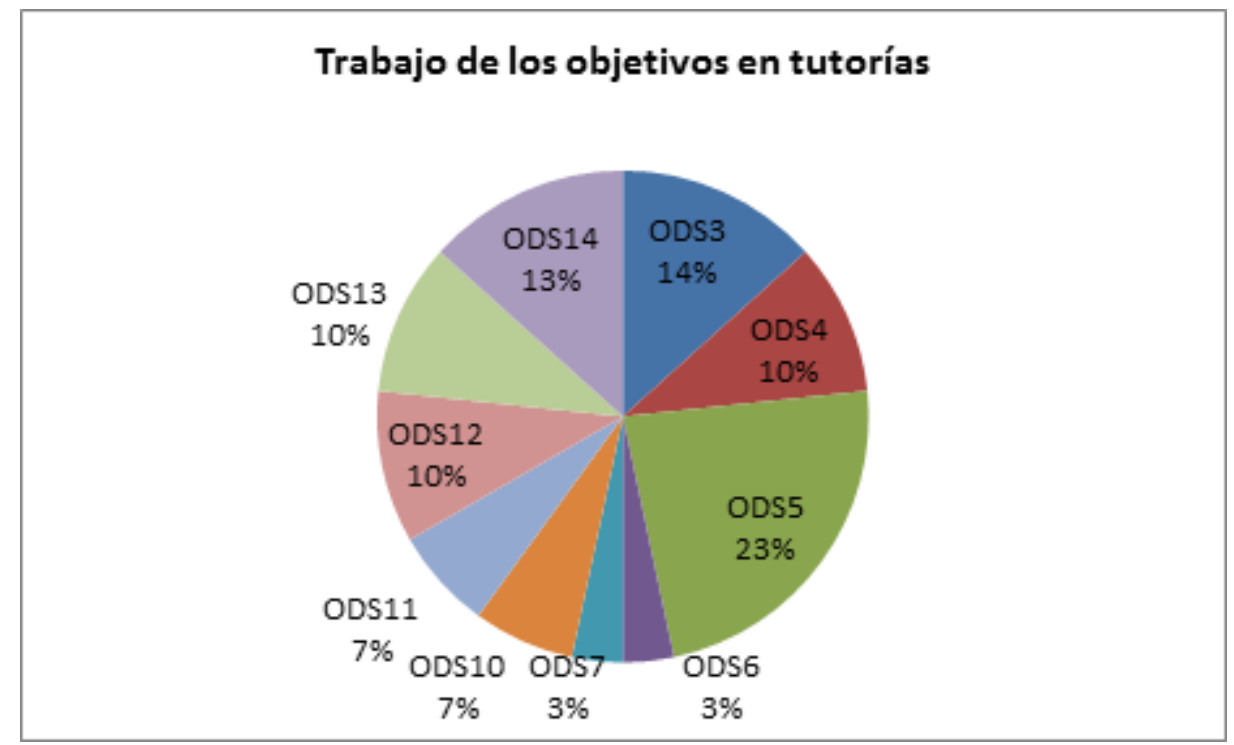

Fuente: Elaboración propia

El ODS que con mayor profundidad se trata en las diferentes asignaturas y tutorías es el 5 (Igualdad de género). El profesorado explica que en clase intentan utilizar lenguaje inclusivo y enseñar en igualdad utilizando diferentes recursos: textos, libros, películas, etc. Esto va en línea con las acciones para la igualdad de género que lleva a cabo el centro dentro del programa Skolae.

Respecto a las asignaturas, aquellas en las que más ODS se trabajan son, por orden, Ciencias Sociales (consecuencia fundamentalmente del proyecto Iturrama Solidario, pero también a través del temario de todos los cursos), Ciencias Naturales (consecuencia fundamentalmente del proyecto Iturrama Verde), Economía (los objetivos se trabajan sobre todo mediante el temario y la realización de un trabajo sobre el consumo responsable en $4 .^{\circ}$ de ESO) y las asignaturas de Valores Éticos, Psicología y Filosofía. Las que menos objetivos tratan son Educación Física y Matemáticas.

\section{Competencias clave para la sostenibilidad mediante las asignaturas}

A partir de los cuestionarios realizados a los profesores, se ha podido determinar también las competencias clave para la sostenibilidad que se adquieren en cada asignatura En la tabla 5 se muestra, en una escala del 0 al 10, cómo se trabajan las competencias clave para la sostenibilidad en cada asignatura. Para que la interpretación sea más gráfica, se ha clasificado por colores: verde fuerte: $8-10 \rightarrow$ Gran profundidad; verde claro: 6-8 $\rightarrow$ Profundidad elevada; amarillo: 4-6 $\rightarrow$ Profundidad media; naranja: 2-4 $\rightarrow$ Profundidad baja, y rojo: $0-2 \rightarrow$ No se menciona. 
Tabla 5. Competencias por asignaturas

\begin{tabular}{|c|c|c|c|c|c|c|c|c|c|}
\hline & 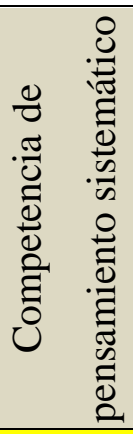 & 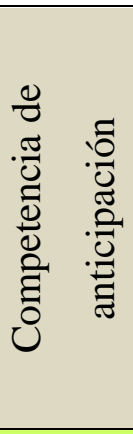 & 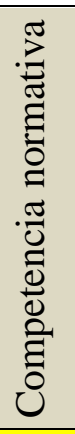 & 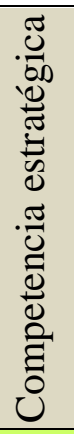 & 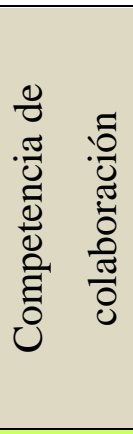 & 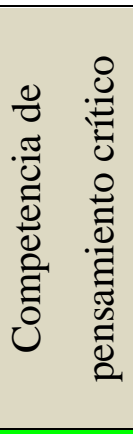 & 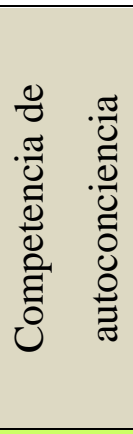 & 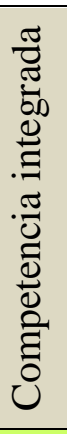 & $\begin{array}{l}0 \\
0 \\
: 0 \\
0 \\
0 \\
0 \\
0 \\
0 \\
0 \\
0\end{array}$ \\
\hline $\begin{array}{l}\text { Ciencias } \\
\text { naturales }\end{array}$ & 5 & 6 & 5.5 & 6 & 6.5 & 8.5 & 6.5 & & 7 \\
\hline $\begin{array}{l}\text { Ciencias } \\
\text { sociales }\end{array}$ & 8.5 & 8.5 & 5.5 & 6 & 7.5 & 9.5 & 5.5 & & 6 \\
\hline Dibujo & 5 & 7.5 & 7.5 & 7.5 & 7.5 & 7.5 & 7.5 & & 7.5 \\
\hline Economía & 10 & 10 & 10 & 7.5 & 10 & 10 & 10 & & 10 \\
\hline $\begin{array}{c}\text { Educación } \\
\text { Física }\end{array}$ & 3.8 & 5 & 5 & 5 & 10 & 5 & 8.8 & & 7.5 \\
\hline $1^{\circ}$ lengua & 4.5 & 3.1 & 4.4 & 2.5 & 5.6 & 5.6 & 4.4 & & 4.4 \\
\hline $\begin{array}{l}\text { Física } \\
\text { química }\end{array}$ & 7.5 & 7.5 & 2.5 & 3.8 & 3.8 & 3.8 & 5 & & 3.8 \\
\hline Filosofía & 7.5 & 5 & 7.5 & 7.5 & 10 & 10 & 7.5 & & 7.5 \\
\hline Inglés & 5.6 & 4.4 & 3.8 & 3.8 & 6.9 & 6.3 & 5 & & 4.4 \\
\hline Matemática & 6.7 & 5.4 & 2.5 & 3.9 & 5 & 3.3 & 2.9 & & 4.2 \\
\hline Tecnología & 5 & 10 & 5 & 10 & 10 & 7.5 & 10 & & 7.5 \\
\hline Media & 6 & 6.6 & 5.4 & 5.6 & 7.5 & 7.0 & 6.6 & & 6.3 \\
\hline
\end{tabular}

Fuente: Elaboración propia

En la figura 8 se muestra el peso de cada una de las competencias en las tutorías. 
Figura 8. Competencias trabajadas en tutoría

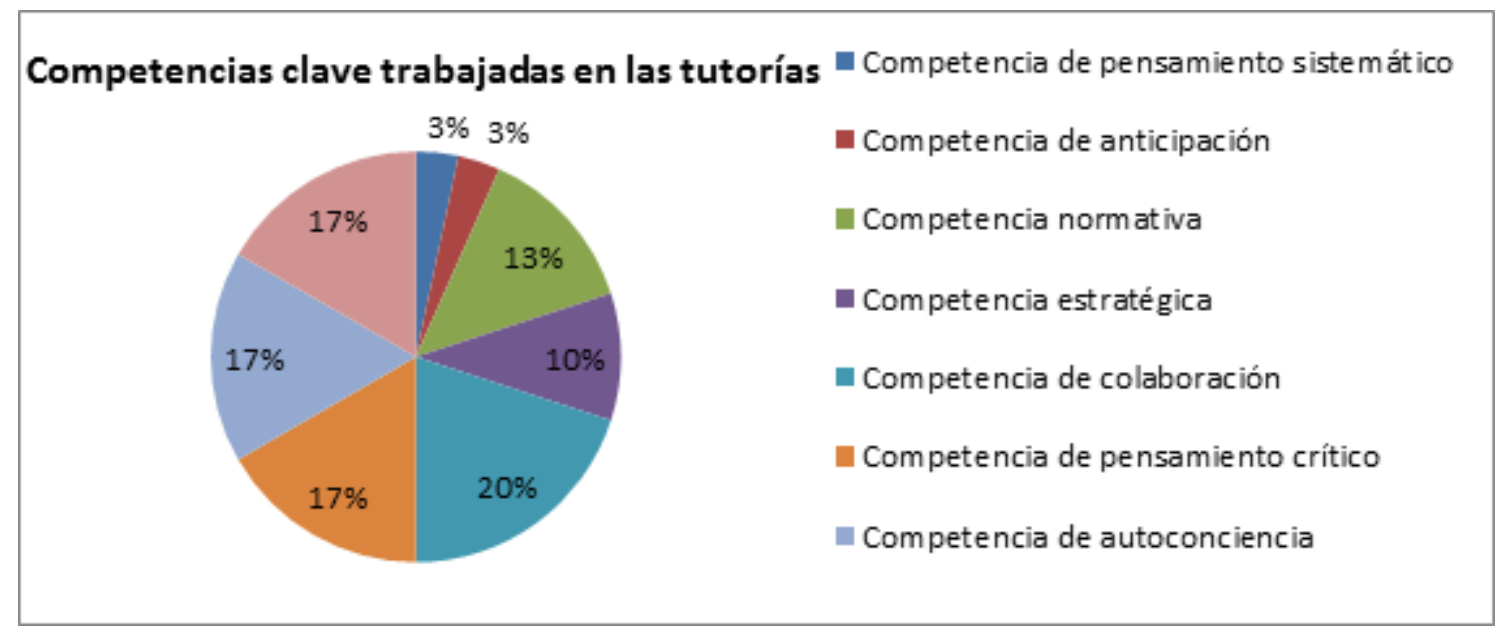

Fuente: Elaboración propia

En general, se transmiten mediante todas las asignaturas todas las competencias clave para la sostenibilidad. La que más se trabaja es la de colaboración. Esto es sobre todo gracias a la metodología CA/AC, que se ha empezado a implementar en el centro. De los comentarios realizados por el profesorado, hay que destacar su actitud positiva ante esta metodología y sus resultados. Para fomentar el resto de las competencias, entre las respuestas del profesorado destacan las siguientes: incrementar el análisis de textos y el visionado de videos y películas con debates en grupo y resolución de problemas.

\section{Resultados de los alumnos}

\section{Conocimiento e interés de los alumnos en los ODS y la EDS}

De todo el alumnado del centro, $41.57 \%$ del alumnado había oído hablar de los objetivos en algún momento. Si se desglosa por ciclos formativos, en el primer ciclo (1. ${ }^{\circ}$ y 2. ${ }^{\circ}$ de la ESO) solo $17.68 \%$ los conocía, mientras que en el segundo ciclo $57.14 \%$ los conocía. Este conocimiento viene dado sobre todo por los programas de televisión y el uso de las redes sociales. Respecto al alumnado de bachillerato, $32.35 \%$ conocía los ODS mediante las fuentes anteriores y también mediante la asignatura de Economía. Los resultados se muestran en la tabla 6 . 
Tabla 6. Conocimiento del alumnado sobre los ODS

\begin{tabular}{|c|c|c|c|r|}
\hline $\begin{array}{c}\text { Conocimiento } \\
\text { previo }\end{array}$ & Total & $\begin{array}{c}\text { Primer } \\
\text { ciclo }\end{array}$ & $\begin{array}{c}\text { Segundo } \\
\text { ciclo }\end{array}$ & Bachillerato \\
\hline Sí & $41.57 \%$ & $17.65 \%$ & $57.14 \%$ & $32.35 \%$ \\
\hline No & $58.43 \%$ & $82.35 \%$ & $42.86 \%$ & $67.65 \%$ \\
\hline
\end{tabular}

Fuente: Elaboración propia

\section{Objetivos trabajados mediante las asignaturas: percepción del alumnado}

A partir de los cuestionarios realizados a los alumnos se ha podido determinar la percepción que el alumnado de diferentes ciclos tiene sobre si los ODS se consideran en las diferentes asignaturas que cursa. En la tabla 7 se muestra la media sobre 10 de cómo el alumnado de cada ciclo percibe que se trabajan los ODS. Para que la interpretación sea más gráfica, se ha clasificado por colores: verde fuerte: 8-10 $\rightarrow$ Gran profundidad; verde claro: 6-8 $\rightarrow$ Profundidad elevada; amarillo: 4-6 $\rightarrow$ Profundidad media; naranja: 2-4 $\rightarrow$ Profundidad baja, y rojo: 0-2 $\rightarrow$ No se menciona. 
Tabla 7. Percepción del alumnado del trabajo de los ODS en la docencia

\begin{tabular}{|c|c|c|c|c|}
\hline ODS & Total & $\begin{array}{c}\text { Primer } \\
\text { ciclo }\end{array}$ & $\begin{array}{c}\text { Segundo } \\
\text { ciclo }\end{array}$ & Bachillerato \\
\hline ODS 1 & $\mathbf{9 . 3 2}$ & 6.93 & 10 & 10 \\
\hline ODS 2 & $\mathbf{6 , 8 1}$ & - & 10 & 9.09 \\
\hline ODS 3 & $\mathbf{9 . 1 1}$ & 9.23 & 8.64 & 9.09 \\
\hline ODS 4 & $\mathbf{7 . 7 1}$ & 5.38 & 8.70 & 8.33 \\
\hline ODS 5 & $\mathbf{1 0}$ & 10 & 10 & 10 \\
\hline ODS 6 & $\mathbf{3 . 8 6}$ & 3.08 & 3.60 & 4.74 \\
\hline ODS 7 & $\mathbf{5 . 0 9}$ & 3.85 & 5 & 6.11 \\
\hline ODS 8 & $\mathbf{6 . 9 8}$ & 1.54 & 7.73 & 10 \\
\hline ODS 9 & $\mathbf{5 . 7 1}$ & 4.62 & 6.82 & 5.24 \\
\hline ODS 10 & $\mathbf{8 . 6 8}$ & 8.46 & 8.64 & 8.89 \\
\hline ODS 11 & $\mathbf{2 . 8 3}$ & - & 4.67 & 3.33 \\
\hline ODS 12 & $\mathbf{6 . 6 0}$ & 3.08 & 7.73 & 7.78 \\
\hline ODS 13 & $\mathbf{6 . 8 8}$ & 7.69 & 8.82 & 4.44 \\
\hline ODS 14 & $\mathbf{5 . 4 3}$ & 4.44 & 8.33 & 3.57 \\
\hline ODS 15 & $\mathbf{5 . 5 0}$ & 3.08 & 5.24 & 5.83 \\
\hline ODS 16 & $\mathbf{8 . 0 4}$ & 6.15 & 8.64 & 8.75 \\
\hline ODS 17 & $\mathbf{6 . 6 7}$ & - & 8.95 & 8.64 \\
\hline
\end{tabular}

Fuente: Elaboración propia

Si se revisa la columna Total (representa la media ponderada), se puede observar que a lo largo de los diferentes cursos se acaban viendo todos los objetivos, pero con diferente intensidad. Comparando entre ciclos, los más jóvenes (primer ciclo) son los que menos objetivos perciben que se trabajan y con menor intensidad. Entre el segundo ciclo y bachillerato la percepción es similar. Esta diferencia entre los resultados del primer ciclo y el resto es consecuencia principalmente del proyecto Iturrama Solidario, que comienza en el segundo ciclo.

Desglosando por asignaturas, el alumnado destaca las siguientes por orden de importancia para el trabajo de los ODS: Ciencias Sociales (mediante Iturrama Solidario y el temario), Ciencias Naturales (mediante Iturrama Verde y el temario), Economía (mediante el temario y un proyecto sobre consumo responsable), Filosofía y Valor Ético (mediante el temario) y tutorías (es la "asignatura" mediante la cual los alumnos aprenden sobre sus salidas laborales y opciones de estudio y se realizan talleres de sexología y 
drogas y alcohol). También destaca que en las asignaturas de idiomas (primeras lenguas y lenguas extranjeras) se trabaja de manera esporádica los ODS, sobre todo mediante lecturas. Las asignaturas en las que menos se trabajan los ODS son Matemáticas y Educación Física. En matemáticas solo mencionan el trabajo realizado para el proyecto de Iturrama Solidario y en Educación Física uno sobre la circulación en bici por la ciudad. Es de resaltar la coincidencia entre la percepción de los profesores y los alumnos en relación con las asignaturas en las que más y menos se trabajan los ODS.

En cuanto a los ODS, el trabajo por la igualdad (ODS 5) llevado por el profesorado en sus asignaturas y las tutorías lo recalca el alumnado en sus respuestas, donde dicen que tratan la igualdad en todas las asignaturas (le dan un 10 en la tabla 5 en todos los ciclos), resaltando los talleres de sexología y el proyecto Iturrama Solidario.

\section{Propuesta de mejora}

Vista la eficacia de los dos proyectos que se llevan a cabo, y las respuestas del profesorado y los alumnos, la propuesta principal que se le hace al centro es la continuación de los proyectos Iturrama Solidario e Iturrama Verde y la puesta en marcha de tres de nuevos proyectos sobre otros temas a tratar en diferentes cursos, y en donde participen el resto de las asignaturas (tabla 8). 
Tabla 8. Proyectos propuestos

\begin{tabular}{|c|c|c|c|c|c|}
\hline Nombre & $\begin{array}{c}\text { Autonomía } \\
\text { Personal }\end{array}$ & $\begin{array}{l}\text { Salud y } \\
\text { Bienestar }\end{array}$ & $\begin{array}{c}\text { Stop } \\
\text { Discriminación }\end{array}$ & $\begin{array}{l}\text { Iturrama } \\
\text { Solidario }\end{array}$ & Iturrama Verde \\
\hline Temas & $\begin{array}{c}\text { Mundo } \\
\text { laboral } \\
\text { Economía } \\
\text { personal } \\
\text { Consumo } \\
\text { responsable }\end{array}$ & $\begin{array}{l}\text { Hacer frente } \\
\text { al estrés } \\
\text { Mente sana } \\
\text { y cuerpo } \\
\text { sano: salud } \\
\text { mental y } \\
\text { nutrición }\end{array}$ & $\begin{array}{c}\text { Religiones } \\
\text { Clases sociales } \\
\text { Tipos de } \\
\text { discriminacione } \\
\text { s y motivos }\end{array}$ & $\begin{array}{c}\text { Pobreza y } \\
\text { hambre en el } \\
\text { mundo } \\
\text { Desigualdad } \\
\text { es } \\
\text { ¿Cómo } \\
\text { ayudan los } \\
\text { países? } \\
\text { ¿Cómo } \\
\text { nosotrxs } \\
\text { podemos } \\
\text { ayudar? }\end{array}$ & $\begin{array}{c}\text { Cambio } \\
\text { climático: } \\
\text { causas, } \\
\text { consecuencias, } \\
\text { efecto en la } \\
\text { vida terrestre y } \\
\text { marítima } \\
\text { 3R } \\
\text { Agua } \\
\text { Energías }\end{array}$ \\
\hline ODS & $4,5,8,12$ & 3,5 & $\begin{array}{c}1,2,3,4,5,11 \\
12,16,17\end{array}$ & $\begin{array}{c}1,2,3,4,5 \\
6,7,8,9,10 \\
11,12,16, \\
17\end{array}$ & $\begin{array}{c}4,6,7,8,9,10 \\
11,12,13,14 \\
15\end{array}$ \\
\hline $\begin{array}{l}\text { Departam } \\
\text { ento } \\
\text { principal }\end{array}$ & Economía & $\begin{array}{l}\text { Educación } \\
\text { Física }\end{array}$ & Filosofía & $\begin{array}{l}\text { Ciencias } \\
\text { Sociales }\end{array}$ & $\begin{array}{c}\text { Ciencias } \\
\text { Naturales + } \\
\text { Tecnología + } \\
\text { Física y } \\
\text { Química }\end{array}$ \\
\hline $\begin{array}{c}\text { Resto de } \\
\text { departame } \\
\text { ntos que } \\
\text { participan }\end{array}$ & Matemáticas & $\begin{array}{l}\text { Ciencias } \\
\text { Naturales }\end{array}$ & Idiomas, Dibujo & $\begin{array}{l}\text { Filosofía, } \\
\text { Dibujo, } \\
\text { Matemática, } \\
\text { Religión, } \\
\text { Idiomas }\end{array}$ & $\begin{array}{c}\text { Dibujo, } \\
\text { Sociales, Física, } \\
\text { Matemática, } \\
\text { Filosofía, } \\
\text { Tecnología }\end{array}$ \\
\hline
\end{tabular}

Fuente: Elaboración Propia

Como se puede observar, entre estos cinco proyectos se trabajarían todos los ODS y con la participación de la mayoría de las asignaturas. Para saber en qué cursos impartirlos se ha tomado en cuenta el interés del alumnado (figura 9). 
Figura 9. Interés del alumnado

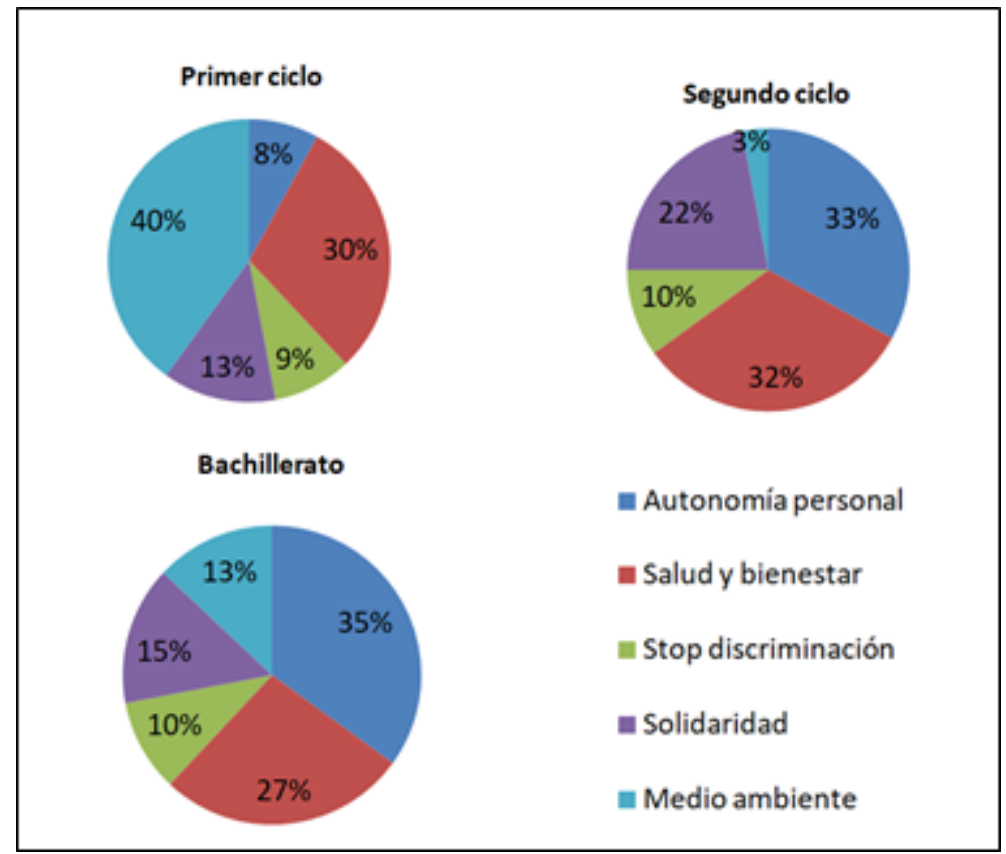

Fuente: Elaboración propia

A continuación, se describe las características de cada proyecto.

\section{Iturrama Solidario}

Este proyecto funciona tal y como está, por lo que lo lógico sería que siguiese igual. Ciencias Sociales será el departamento que lo lleve y el curso principal donde se desarrolle, $3 .^{\circ}$ de la ESO. Se puede observar en la figura 9 que la suma del interés del alumnado en Stop Discriminación y Solidaridad tiene un peso de $32 \%$ en el segundo ciclo, el mayor de los tres niveles educativos, lo que demuestra la influencia de este proyecto.

\section{Iturrama Verde}

Si observamos los diagramas de interés del alumnado, se puede observar que el alumnado del primer ciclo es el que mayor interés tiene en temas medioambientales, debido a que actualmente Iturrama Verde se trabaja en $1 .^{\circ}$ de la ESO. Por lo tanto, se propone seguir trabajándolo en $2 .^{\circ}$ de la ESO para que no decaiga el interés de los estudiantes en temas medioambientales. El departamento principal, como hasta ahora, sería Ciencias Naturales, pero trabajando más con el de Física y Química (se empieza a dar en segundo ciclo), Tecnología y Dibujo. 


\section{Autonomía Personal}

Mediante esta nueva propuesta se pretende que el alumnado salga del centro entendiendo el mercado laboral y teniendo las nociones básicas para llevar su propia economía. Por ejemplo, saber realizar la declaración de la renta, elaborar presupuestos, confeccionar facturas, etc. Este tema es muy reclamado por el alumnado, especialmente en el segundo ciclo $(33 \%)$ y bachillerato $(35 \%)$. Teniendo en cuenta esto, se podría realizar el proyecto en dos cursos: $4 .^{\circ}$ de la ESO (para una parte del alumnado es el último curso que está en el centro) y $2 .^{\circ}$ de bachillerato. Aunque sea el departamento de Economía el encargado de estructurar el proyecto, podrían participar otros departamentos también, sobre todo Matemáticas, y utilizar las horas de tutoría. Su implicación será muy importante, ya que Economía es una asignatura optativa y no la cursa todo el alumnado.

\section{Stop Discriminación}

Este proyecto se plantea para $1 .^{\circ}$ de bachillerato y como continuidad de lo tratado en Iturrama Solidario. Aunque haya un curso en medio ( $4 .{ }^{\circ}$ de la ESO), convendría dejarlo así para poder tratar en este el tema económico. El departamento encargado para este proyecto sería Filosofía, mediante las asignaturas de Filosofía (es en $1 .^{\circ}$ de bachillerato cuando se comienza a dar esta materia), y Valor Ético. El objetivo es seguir trabajando los objetivos tratados en $3 .^{\circ}$ de la ESO, pero de forma más profunda y madura, acercándolo también a las desigualdades que existen en nuestra sociedad.

\section{Salud y Bienestar}

Los temas relacionados con la salud y el bienestar tienen gran interés para el alumnado de todos los cursos, como se puede observar en los diagramas sectoriales. El departamento principal encargado de este proyecto sería Educación Física. No sería un proyecto solo para un curso, sino para ser tratado en todos los cursos. Se podrían tratar temas como nutrición, enfermedades mentales y cómo hacer frente al estrés (los ataques de ansiedad y estrés son cada vez más comunes entre el alumnado).

Como se puede observar, para $2 .^{\circ}$ de bachillerato no se ha propuesto un proyecto en concreto, aunque participaría en el de Salud y Bienestar y en el de Autonomía Personal. En este curso tanto el alumnado como el profesorado está sometido a un gran nivel de presión debido a las pruebas de acceso a la universidad y no sería prudente llevar a cabo algún proyecto. 


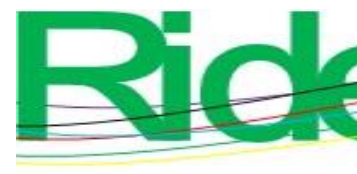

Revista Iberoamericana para la Investigación y el Desarrollo Educativo ISSN 2007 - 7467

Para que los proyectos planteados funcionen correctamente, es fundamental la coordinación y formación del profesorado, y ese es uno de los puntos más débiles de este centro (y la mayoría de los centros públicos). El alto grado de interinidad dificulta la continuidad de los proyectos y supone una formación constante que no todos los años se puede realizar de manera eficiente. Cada dos cursos, los interinos preparan las oposiciones, priorizando estos estudios a los proyectos del centro.

Para que los proyectos se implementen de manera fructífera se sugiere lo siguiente:

- Los encargados de los proyectos deberían ser funcionarios con destino en el centro. Estos recibirían la formación inicial sobre los ODS y la EDS y serían los encargados de formar al resto de participantes en su proyecto, tanto de su departamento como de otros.

- La formación necesaria para la realización de los proyectos debería realizarse en septiembre. En vez de ser una formación general para todo el profesorado, debería hacerse teniendo en cuenta el curso en el que impartirá clases el docente y el proyecto en el que participará.

- $\quad$ Para que con el cambio del profesorado de un curso a otro no se pierda la dinámica seguida y lo aprendido, sería recomendable llevar diarios de las actividades realizadas en cada asignatura por cada proyecto y que estos registros fueran guardados por el encargado del proyecto.

\section{Discusión}

Los resultados obtenidos permiten identificar las acciones que se llevan a nivel de centro relacionadas con la sostenibilidad y proponer otras nuevas para cubrir las carencias detectadas, así como analizar la percepción que tienen profesores y alumnos de diferentes niveles sobre el grado en el que se profundiza en la enseñanza de los ODS en cada asignatura. Es importante resaltar las limitaciones del estudio: se centra en la participación de los profesores y alumnos, que, si bien fue mayoritaria, no abarcó a la totalidad del centro.

La novedad y relevancia de estos resultados estriba en que no existe en nuestro conocimiento ninguna investigación como la mostrada en este artículo que 1) analice el trabajo realizado para alcanzar los ODS en un centro de secundaria desde un punto de vista holístico, tanto a nivel de centro como en cada asignatura, considerando las percepciones de la dirección, el cuerpo docente y alumnado, y 2) se propongan mejoras 
que permitan alinear la estrategia de la dirección del centro con la educación para la sostenibilidad, y transformarla en una serie de planes de acción concretados en diferentes proyectos que involucran a los profesores y alumnos en la consecución de todos los ODS.

Por lo tanto, el trabajo aquí presentado puede tomarse como base para realizar futuros análisis y mejoras similares en otros centros, teniendo en cuenta la metodología seguida en el presente trabajo y los cuestionarios realizados que se muestran en el anexo de este artículo.

\section{Conclusiones}

El cumplimiento de los ODS es fundamental para asegurar el bienestar de la sociedad y de las generaciones futuras. Para alcanzarlos, la educación es clave, ya que, además de ser uno de los objetivos sostenibles en sí misma, es una de las herramientas principales para conseguir concienciar y comprometer a la ciudadanía. Por lo tanto, es necesario revisar en qué grado se están trabajando actualmente los ODS en los colegios e institutos, identificando las fortalezas y debilidades, así como proponiendo mejoras que permitan encaminar su actuación hacia una EDS de forma integral.

En este artículo se muestra el análisis de la situación actual en un instituto público español mediante tres cuestionarios elaborados para tal fin, identificando las acciones que se llevan a nivel de centro relacionadas con la sostenibilidad y la percepción que tienen profesores y alumnos de diferentes niveles sobre el grado en el que se profundiza en la enseñanza de los ODS y en la transmisión de las competencias clave para el desarrollo sostenible. Esto ha permitido identificar cuántos ODS trabaja cada asignatura (las asignaturas que más ODS trabajan son Ciencias Sociales, Ciencias Naturales, Economía y Filosofía, y las que menos, Educación Física y Matemáticas). También se ha identificado el grado en que cada ODS es trabajado en cada ciclo formativo.

Como resultado, se ha procedido a proponer a la dirección del centro cinco proyectos (la ampliación de los proyectos Iturrama Solidario e Iturrama Verde, así como tres nuevos) que permitirán que se trabajen todos los ODS de una manera integral y en mayor medida, además de implicar a un mayor número de asignaturas. De este modo se reforzarán los ODS en los alumnos, ya que, como se ha comprobado, su interés decae si no se repiten durante toda su formación. Por ejemplo, el interés en la sostenibilidad del medio ambiente es mayor en los alumnos de primer ciclo que en los restantes porque están trabajando en el proyecto Iturrama Verde. 
Este caso de estudio puede servir como ejemplo para que otros centros formativos realicen un análisis de su situación actual, y definan nuevos proyectos de mejora alineados con el cumplimiento de los ODS, evitando así una de las carencias que tenía la dirección de IES Iturrama, ya que determinaba los proyectos a llevar a cabo a nivel de centro sin tener en cuenta su relación con los ODS.

\section{Referencias}

Aneas, M. S., Ferreiro, C., Jimenez, J., Matin, J. L., Rico, L., Rivera, V. y Vidal, M. D. (2017). El desafío de los ODS en secundaria. Madrid, España: Agencia Española de Cooperación Internacional para el Desarrollo (AECID), Ministerio de Asuntos Exteriores y de Cooperación

Anyolo, E. (2018). Implementing Education for Sustainable Development in Namibia: School Teachers' Perceptions and Teaching Practices. Journal of Teacher Education for Sustainability, 20(1), 64-81

Díaz, V. (2019). Tipos de encuestas y diseños de investigación. Recuperado de http://www.unavarra.es/personal/vidaldiaz/pdf/tipos_encuestas.PDF.

García, J. y Rendón, C. M. G. (2018). Percepciones y acciones de las y los estudiantes de la Universidad Autónoma del Estado de México respecto a la educación en el desarrollo sostenible. RIDE. Revista Iberoamericana para la Investigación y el Desarrollo Educativo, 9(17) 225-255

Gobierno de Navarra (2017). Skolae. Berdin bidean. Creciendo en igualdad. Navarra, España: Departamento de Educación del Gobierno de Navarra.

OpenCourseWare. (2017). Tema 2. Métodos de valoración. Cuestionarios. Recuperado de https://ocw.unican.es/mod/page/view.php?id=498\#2.

ONU (2015). Resolución aprobada por la Asamblea General el 25 de septiembre de 2015. Recuperado de https://undocs.org/es/A/RES/70/1.

Pujolàs, P. y Lago, J. R. (coords.) (2012). El programa CA/AC ("Cooperar para Aprender / Aprender a Cooperar"). Implementación del aprendizaje cooperativo en el aula. España: Universidad de Vic.

Rabiatul, A. (2012). Teachers' Knowledge of Education for Sustainable Development. Paper presented at the $11^{\text {th }}$ International Annual Symposium on Sustainability Science and Management. Terengganu, July 9-11, 2012. 
SurveyMonkey. (2019). Preguntas de opción múltiple: todo lo que necesitas saber.

Recuperado de https://es.surveymonkey.com/mp/multiple-choice-questionseverything-you-need-to-know/.

Typeform (2019). Tipos de preguntas para encuestas eficaces. Recuperado de https://www.typeform.com/es/encuestas/tipos-de-preguntas/.

Unesco (1992). Conferencia de las Naciones Unidas sobre el Desarrollo Sostenible. Río de Janeiro, 3 al 14 de junio. Recuperado de http://www.unesco.org/education/nfsunesco/pdf/RIO_S.PDF

Unesco (2015a). Replantear la educación. ¿Hacia un bien común mundial? París, Francia: Organización de las Naciones Unidas para la Educación, la Ciencia y la Cultura. Recuperado de https://unesdoc.unesco.org/ark:/48223/pf0000232697.

Unesco (2015b). Declaración de Incheon y marco de acción para la realización del Objetivo de Desarrollo Sostenible 4. Organización de las Naciones Unidas para la Educación, la Ciencia y la Cultura. Recuperado de https://unesdoc.unesco.org/ark:/48223/pf0000245656_spa.

Unesco (2017). Educación para los Objetivos de Desarrollo Sostenible. Objetivos de aprendizaje. París, Francia: Organización de las Naciones Unidas para la Educación, la Ciencia y la Cultura. Recuperado de https://unesdoc.unesco.org/ark:/48223/pf0000252423.

Unesco (2019). Sobre la Unesco. Recuperado de https://es.unesco.org/aboutus/introducing-unesco.

Vilches, A. (2012). La educación para la sostenibilidad en la universidad: el reto de la formación para el profesorado. Profesorado. Revista de Currículum y Formación del Profesorado, 16(2), 25-43.

Watson, A. (2017). Sustainability Education in Primary and Secondary Schools: Great Needs and Possible Solutions. (thesis). University of Tennessee, Knoxville. Retrieved from https://trace.tennessee.edu/cgi/viewcontent.cgi?article=3047\&context=utk_chan honoproj.

Solís, C. (2015). La educación para la sostenibilidad en la formación del profesorado. ¿Qué estamos haciendo? Foro de Educación, 13(19), 165-192 


\section{Anexo 1. Cuestionario para la dirección}

\section{Introducción}

Se trata de un cuestionario para analizar la integración de los Objetivos para el Desarrollo Sostenible (ODS) en la educación, con el fin de presentar un análisis de un centro concreto (IES Iturrama) en materia de educación para el desarrollo sostenible (EDS).

Este cuestionario consta de las siguientes partes:

1. Preguntas personales.

2. Conocimiento sobre los ODS y la EDS.

3. Interés personal.

4. Formación al profesorado.

\section{Preguntas personales}

1.1 Cargo en el centro:

1.2 Años como docente:

1.3 Años en el centro (contando este como uno):

1.4 Años en el cargo (contando este como uno):

\section{Conocimiento sobre los ODS y la EDS}

\section{1 ¿Cuánto considera que sabe sobre los ODS?}

Considero que sé mucho sobre el tema y que soy capaz de poder identificar todos los objetivos. (Conocimiento total)

$\square$ Sé en qué consisten y podría identificar la mayoría de ellos. (Conocimiento elevado)

$\square$ Sé en qué consisten aunque no sea capaz de identificarlos. (Conocimiento medio)

$\square \quad$ He oído hablar de ellos pero solo tengo una idea vaga de lo que es. (Conocimiento bajo)

$\square \quad$ No he oído hablar de ellos. (Conocimiento nulo)

2.2 Por favor, explique qué sabe sobre los ODS; qué le viene en mente al escuchar este concepto.

\section{3 ¿Cuánto considera que sabe sobre la EDS?}

Considero que sé mucho sobre el tema y soy capaz de explicar los puntos de este enfoque, sus competencias, contenidos y objetivos. (Conocimiento total)

Sé en qué consiste y podría dar una explicación detallada del tema. (conocimiento elevado) Sé en qué consiste y podría dar una explicación general del tema. (Conocimiento medio) Me suena el concepto pero no podría definirlo bien. (Conocimiento bajo)

No he oído hablar del tema. (Conocimiento nulo)

2.4 Por favor, explique qué sabe sobre la EDS; qué le viene en mente al escuchar este concepto: 


\section{Interés personal}

3. 1 ¿Cuál es su nivel de interés en este tema?

Muy alto

$\square \quad$ Alto

$\square \quad$ Indiferente

$\square$ Bajo

$\square \quad$ Muy bajo

3.2 ¿Ha recibido alguna formación sobre sostenibilidad o EDS?

No

Sí. Especifique cuál y dónde:

\section{Formación del profesorado}

4.1 ¿Cómo de importante considera que es que el profesorado esté formado en los ODS y la EDS?

Imprescindible

Importancia elevada

Neutral

Poco importante

No es relevante

4.2 Indique el interés que cree que puede tener el profesorado en realizar una formación sobre el tema:

Muy alto

Alto

Indiferente

Bajo

Muy bajo

4.3 Indique las razones para las respuestas anteriores:

4.4 ¿Cómo considera que debería ser la formación ofrecida al profesorado?

Muchas gracias por su participación y su tiempo para la realización de esta encuesta. 


\section{Anexo 2. Cuestionario para el profesorado}

\section{Introducción}

Se trata de un cuestionario para analizar la integración de los Objetivos para el Desarrollo Sostenible (ODS) en la educación, con el fin de presentar un análisis de un centro concreto (IES Iturrama) en materia de educación para el desarrollo sostenible (EDS).

Este cuestionario consta de las siguientes partes:

1. Preguntas personales

2. Conocimiento general sobre los ODS y la EDS

3. Preguntas relacionadas con cada objetivo

4. Competencias clave para la sostenibilidad

5. Interés en el tema y formación al profesorado

\section{Preguntas personales}

1.1 Años en la docencia:

1.2 Años en el centro:

1.3 ¿Es tutor? Sí/No

Si es tutor conteste a las preguntas en relación con su asignatura y horas de tutoría

1.3 Marque la casilla correcta: $\square$ Funcionario/a $\quad \square$ Interino/a

1.4 Indique el departamento al que pertenece:

\section{Conocimiento sobre los ODS y la EDS}

\section{1 ¿Cuánto considera que sabe sobre los ODS?}

Considero que sé mucho sobre el tema y que soy capaz de poder identificar todos los objetivos. (Conocimiento total)

Sé en qué consisten y podría identificar la mayoría de ellos. (Conocimiento elevado)

$\square$ Sé en qué consisten aunque no sea capaz de identificarlos. (Conocimiento medio)

$\square \quad$ He oído hablar de ellos pero solo tengo una idea vaga de lo que es. (Conocimiento bajo)

$\square \quad$ No he oído hablar de ellos. (Conocimiento nulo)

2.2 Por favor, explique qué sabe sobre los ODS; qué le viene en mente al escuchar este concepto.

\section{3 ¿Cuánto considera que sabe sobre la EDS?}

Considero que sé mucho sobre el tema y soy capaz de explicar los puntos de este enfoque, sus competencias, contenidos y objetivos. (Conocimiento total)

Sé en qué consiste y podría dar una explicación detallada del tema. (Conocimiento elevado)

Sé en qué consiste y podría dar una explicación general del tema. (Conocimiento medio)

Me suena el concepto pero no podría definirlo bien. (Conocimiento bajo) 
No he oído hablar del tema. (Conocimiento nulo)

\subsection{Por favor, explique qué sabe sobre la EDS; qué le viene en mente al escuchar este concepto:}

\section{Preguntas relacionadas con cada objetivo}

\subsection{Fin de la pobreza}

3.1.1 ¿Qué temas relacionados con la pobreza ha tratado?

3.1.2 ¿Cómo ha trabajado el tema? Un proyecto de la asignatura (especifique cuál), proyecto del centro (especifique cuál), lecturas, película, libro... Explique brevemente el trabajo realizado:

3.1.3 Indique la profundidad en la que en la que considera que trabaja mediante su asignatura este objetivo:

Gran profundidad

Profundidad elevada

Profundidad media

Profundidad baja (se menciona de manera esporádica)

No se habla

\subsection{Hambre cero}

3.2.1 ¿Trabaja mediante su asignatura temas relacionados con el hambre en el mundo? ¿Qué temas?

3.2.2 ¿Cómo ha trabajado el tema? Un proyecto de la asignatura (especifique cuál), proyecto del centro (especifique cuál), lecturas, película, libro... Explique brevemente el trabajo realizado:

3.2.3 Indique la profundidad en la que en la que considera que trabaja mediante su asignatura este objetivo:

Gran profundidad

Profundidad elevada

Profundidad media

Profundidad baja (se menciona de manera esporádica)

No se habla

\subsection{Salud y bienestar}

3.3.1 ¿Considera que mediante su asignatura ayuda a que el alumnado conozca diferentes aspectos relacionados con la salud mental?, ¿qué temas diría que trata? (diferentes enfermedades mentales, consumo de droga y alcohol, cómo cuidar nuestra salud mental...).

3.3.2 ¿Cómo ha trabajado el tema? Un proyecto de la asignatura (especifique cuál), proyecto del centro (especifique cuál), lecturas, película, libro... Explique brevemente el trabajo realizado

3.3.3 Indique la profundidad en la que en la que considera que trabaja mediante su asignatura este objetivo:

Gran profundidad 
Profundidad elevada

Profundidad media

Profundidad baja (se menciona de manera esporádica)

No se habla

\subsection{Educación de calidad}

3.4.1 ¿Ha hablado con su alumnado mediante su asignatura sobre la continuación de su educación y las opciones que tienen en el sistema? ¿Cómo ha trabajado el tema?

3.4.2 ¿Ha comentado en su clase la importancia de la educación para poder progresar individualmente y la sociedad en su conjunto? ¿Cómo ha tratado el tema?

3.4.3 Indique la profundidad en la que en la que considera que trabaja mediante su asignatura este objetivo:

Gran profundidad

Profundidad elevada

Profundidad media

Profundidad baja (se menciona de manera esporádica)

No se habla

\subsection{Igualdad de género}

3.5.1 ¿Cómo intenta concienciar a su alumnado sobre la igualdad de género? ¿Qué temas trata y mediante qué técnicas?

3.5.2 Del 1 al 5, siendo 5 el máximo, ¿cómo valora el proyecto de Skolae?

3.5.3 Indique la profundidad en la que en la que considera que trabaja mediante su asignatura este objetivo:

Gran profundidad

Profundidad elevada

Profundidad media

Profundidad baja (se menciona de manera esporádica)

No se habla

\subsection{Agua limpia y saneamiento}

3.6.1 ¿Habla en su asignatura de la importancia del agua para el ser humano y la vida en general? ¿Mediante qué temas?

3.6.2 ¿Cómo ha trabajado el tema? Un proyecto de la asignatura (especifique cuál), proyecto del centro (especifique cuál), lecturas, película, libro... Explique brevemente el trabajo realizado:

3.6.3 Indique la profundidad en la que en la que considera que trabaja mediante su asignatura este objetivo:

Gran profundidad

Profundidad elevada

Profundidad media 
Profundidad baja (se menciona de manera esporádica)

No se habla

\subsection{Energía asequible y no contaminante}

3.7.1 ¿Qué temas asociados con las energías renovables considera que se tratan mediante su asignatura?

3.7.2 ¿Cómo ha trabajado el tema? Un proyecto de la asignatura (especifique cuál), proyecto del centro (especifique cuál), lecturas, película, libro... Explique brevemente el trabajo realizado:

3.7.3 Indique la profundidad en la que en la que considera que trabaja mediante su asignatura este objetivo:

Gran profundidad

Profundidad elevada

Profundidad media

Profundidad baja (se menciona de manera esporádica)

No se habla

\subsection{Trabajo decente y crecimiento económico}

3.8.1 ¿Trabaja mediante su asignatura temas relacionados con el mercado laboral, tales como desempleo, emprendimiento, economía sostenible, finanzas propias, condiciones laborales, desigualdad salarial...?

3.8.2 ¿Cómo ha trabajado el tema? Un proyecto de la asignatura (especifique cuál), proyecto del centro (especifique cuál), lecturas, película, libro... Explique brevemente el trabajo realizado:

3.8.3 Indique la profundidad en la que en la que considera que trabaja mediante su asignatura este objetivo:

Gran profundidad

Profundidad elevada

Profundidad media

Profundidad baja (se menciona de manera esporádica)

No se habla

\subsection{Industria, innovación e infraestructura}

3.9.1 ¿Explica mediante su asignatura las mejoras que puede traer la tecnología en el medio ambiente, sociedad y economía (transporte eléctrico, producción menos contaminante...)?

3.9.2 ¿Cómo ha trabajado el tema? Un proyecto de la asignatura (especifique cuál), proyecto del centro (especifique cuál), lecturas, película, libro... Explique brevemente el trabajo realizado:

3.9.3 Indique la profundidad en la que en la que considera que trabaja mediante su asignatura este objetivo:

Gran profundidad

Profundidad elevada

Profundidad media 
Profundidad baja (se menciona de manera esporádica)

No se habla

\subsection{Reducción de las desigualdades}

3.10.1 ¿Cómo trabaja mediante su asignatura la necesidad de reducir las desigualdades causadas por las dimensiones como género, religión, clase, orientación sexual, clase económica...? Un proyecto de la asignatura (especifica cuál), proyecto del centro (especifica cuál), lecturas, película, libro... Explique brevemente el trabajo realizado:

3.10.2 Indique la profundidad en la que en la que considera que trabaja mediante su asignatura este objetivo:

Gran profundidad

Profundidad elevada

Profundidad media

Profundidad baja (se menciona de manera esporádica)

No se habla

\subsection{Ciudades y comunidades sostenibles}

3.11.1 ¿Considera que mediante su asignatura trabaja temas tales como el transporte sostenible, la adaptación de la ciudad para todos y todas (sin importar edad capacidad, sexo, religión...), huertas urbanas...?

3.11.2 ¿Cómo ha trabajado el tema? Un proyecto de la asignatura (especifique cuál), proyecto del centro (especifique cuál), lecturas, película, libro... Explique brevemente el trabajo realizado: 3.11.3 Indique la profundidad en la que en la que considera que trabaja mediante su asignatura este objetivo:

Gran profundidad

Profundidad elevada

Profundidad media

Profundidad baja (se menciona de manera esporádica)

No se habla

\subsection{Producción y consumo responsable}

3.12.1 ¿Trabaja mediante su asignatura las consecuencias de los actos individuales en el medio ambiente, sociedad y economía? Si habla, ¿de qué tipo de actos habla y cómo (por ejemplo, diferentes tipos de transporte, consumo responsable, uso de energías de manera sostenible, etiquetado de los productos, las 3R (reciclar, reutilizar, reducir...)?

3.12.2 ¿Cómo ha trabajado el tema? Un proyecto de la asignatura (especifique cuál), proyecto del centro (especifique cuál), lecturas, película, libro... Explique brevemente el trabajo realizado: 3.12.3 Indique la profundidad en la que en la que considera que trabaja mediante su asignatura este objetivo:

Gran profundidad 
Profundidad elevada

Profundidad media

Profundidad baja (se menciona de manera esporádica)

No se habla

\subsection{Acción por el clima}

3.13.1 ¿Cómo trabaja mediante su asignatura el cambio climático?

3.13.2 Indique la profundidad en la que en la que considera que trabaja mediante su asignatura este objetivo:

Gran profundidad

Profundidad elevada

Profundidad media

Profundidad baja (se menciona de manera esporádica)

No se habla

\subsection{Vida submarina}

3.14.1 ¿Trata con su alumnado temas relacionados con la vida submarina, los efectos de la actividad humana en ella y su conservación? ¿Cómo?

3.14.2 Indique la profundidad en la que en la que considera que trabaja mediante su asignatura este objetivo:

Gran profundidad

Profundidad elevada

Profundidad media

Profundidad baja (se menciona de manera esporádica)

No se habla

\subsection{Vida de ecosistemas terrestres}

3.15.1 ¿Trata con su alumnado temas como la deforestación, extinción de especies, sobreexplotación y otras actividades que afectan a los ecosistemas terrestres? ¿Cómo?

3.15.2 Indique la profundidad en la que en la que considera que trabaja mediante su asignatura este objetivo:

Gran profundidad

Profundidad elevada

Profundidad media

Profundidad baja (se menciona de manera esporádica)

No se habla

\subsection{Paz, justicia e instituciones sólidas}

3.16.1 ¿Habla mediante su asignatura de temas relacionados con la paz, justicia, sistema judicial y/o derechos humanos? ¿Cómo? 
3.16.2 Indique la profundidad en la que en la que considera que trabaja mediante su asignatura este objetivo:

Gran profundidad

Profundidad elevada

Profundidad media

Profundidad baja (se menciona de manera esporádica)

No se habla

\subsection{Alianzas para lograr objetivos}

3.17.1 ¿Habla con su alumnado sobre las alianzas que existen para lograr los objetivos vistos (organizaciones como Naciones Unidas, tratados para hacer frente al cambio climático, organizaciones no gubernamentales...)? ¿Cómo?

3.17.2 Indique la profundidad en la que en la que considera que trabaja mediante su asignatura este objetivo:

Gran profundidad

Profundidad elevada

Profundidad media

Profundidad baja (se menciona de manera esporádica)

No se habla

\section{Competencias clave para la sostenibilidad}

Indique en qué medida se ajustan las siguientes afirmaciones a su asignatura

4.1 Proporciono herramientas adecuadas para que el alumnado sea capaz de hacer frente a situaciones de incertidumbre.

Totalmente en desacuerdo

En desacuerdo

Ni de acuerdo, ni en desacuerdo

De acuerdo

Totalmente de acuerdo

4.2 Preparo al alumnado para que sean capaces de anticipar diferentes escenarios futuros y poder tomar decisiones que les a cada uno de estos escenarios:

Totalmente en desacuerdo

En desacuerdo

Ni de acuerdo, ni en desacuerdo

De acuerdo

Totalmente de acuerdo

4.3 Hablo con el alumnado de los conflictos de interés que se dan en diferentes aspectos de la vida, en el ámbito político, personal y económico. 
Totalmente en desacuerdo

En desacuerdo

Ni de acuerdo, ni en desacuerdo

De acuerdo

Totalmente de acuerdo

4.4 Desarrollo trabajos o proyectos que impulsan al alumnado a tomar acciones encaminadas a la sostenibilidad.

Totalmente en desacuerdo

En desacuerdo

Ni de acuerdo, ni en desacuerdo

De acuerdo

Totalmente de acuerdo

4.5 Desarrollo trabajos/proyectos mediante metodologías colaborativas y de cooperación.

Totalmente en desacuerdo

En desacuerdo

Ni de acuerdo, ni en desacuerdo

De acuerdo

Totalmente de acuerdo

4.6 Mediante mi asignatura ayudo a que el alumnado desarrolle su juicio crítico tanto con sus acciones como con la sociedad.

Totalmente en desacuerdo

En desacuerdo

$\square \quad$ Ni de acuerdo, ni en desacuerdo

$\square \quad$ De acuerdo

Totalmente de acuerdo

4.7 Mediante mi asignatura se ayuda a que el alumnado se conozca a sí mismo y a entender las consecuencias de sus actos.

Totalmente en desacuerdo

En desacuerdo

Ni de acuerdo, ni en desacuerdo

De acuerdo

Totalmente de acuerdo

4.8 Mediante mi asignatura el alumnado conoce y entiende los diferentes problemas sociales, económicos y medioambientales que existen.

Totalmente en desacuerdo

En desacuerdo 
Ni de acuerdo, ni en desacuerdo

De acuerdo

Totalmente de acuerdo

5. Formación al profesorado

5.1 ¿Qué importancia cree que tiene tratar estos objetivos y competencias en tu asignatura?

Muy alta

Alta

$\square \quad$ Indiferente

$\square$ Baja

$\square$ Irrelevante

5.2 ¿Ha recibido alguna formación sobre sostenibilidad o EDS?

No

$\square \quad$ Sí. Especifique cuál y dónde:

5.3 ¿Cómo de importante considera que es que el profesorado esté formado en los ODS y la EDS?

Imprescindible

Importancia elevada

Indiferente

Poco importante

No es relevante

5.4 Indique si estaría dispuesto a realizar un curso sobre los ODS y la Educación Sostenible para el Desarrollo. Indique en qué condiciones estaría dispuesto o dispuesta a realizarlo (gratuito o de pago, online presencial, solo si es obligatorio, si cuenta para las oposiciones, etc.):

Muchas gracias por su participación y su tiempo para la realización de esta encuesta. 


\section{Anexo 3. Cuestionario para el alumnado}

\section{Introducción:}

Mediante este cuestionario se quiere recoger vuestro conocimiento sobre los Objetivos para el Desarrollo Sostenible (ODS).

Estos objetivos los ha propuesto Naciones Unidas y deben ser conseguidos para el año 2030. Se trata de objetivos a lograr en temas sociales, medioambientales y económicos. Son los siguientes 17 objetivos:

Figura AIII.1 ODS
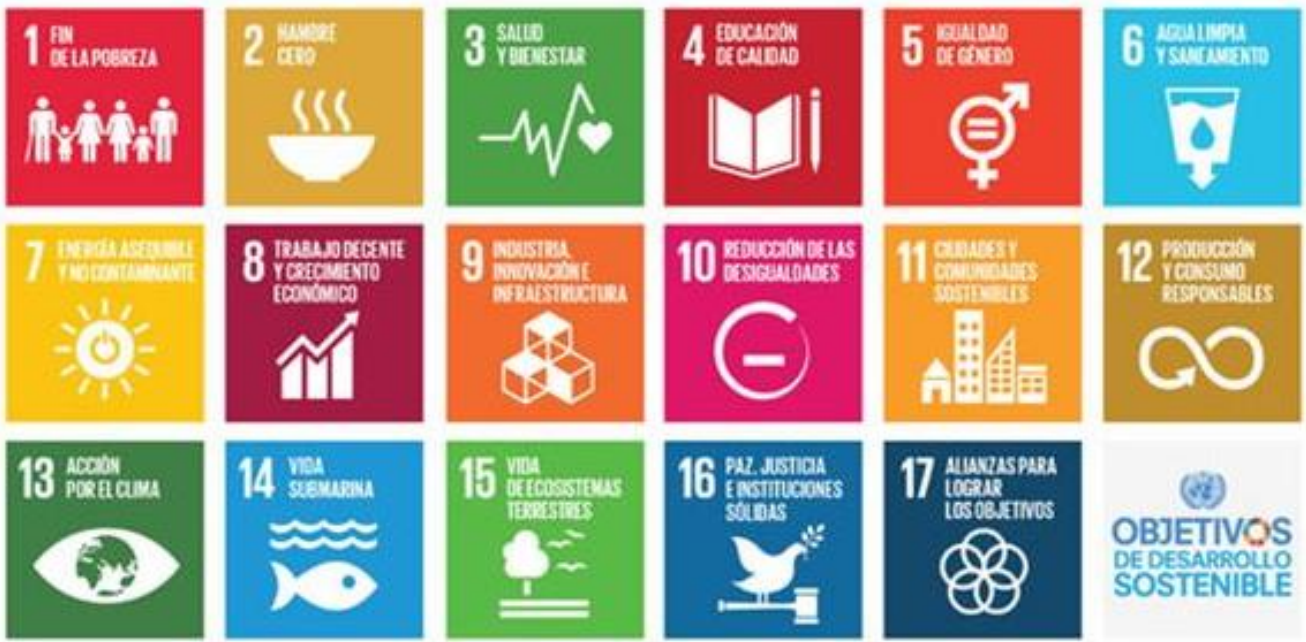

OBJETIVOS

DE DESARROLLO SOSTENIBLE

Fuente: https://www.undp.org/content/undp/es/home/sustainable-development-goals.html

¿Los conocías?

$\square \quad$ No

$\square \quad$ Sí. ¿Dónde has escuchado hablar de ellos?

En el instituto, mediante diferentes proyectos y asignaturas trabajáis algunos de estos objetivos, aunque no se diga de forma explícita que los estéis trabajando.

En este cuestionario se os pregunta por cada objetivo: en qué asignatura los veis, qué temas y cómo. Finalmente, se os preguntará por vuestras preferencias en temas relacionados con los ODS. El cuestionario dura alrededor de 20 minutos.

¡Muchas gracias por tu colaboración!

Empecemos por la primera pregunta....

¿En qué curso estás?

Pasemos a las siguientes...

\section{ODS 1: Fin de la Pobreza}

1.1 De los siguientes temas relacionados con la pobreza, ¿cuáles consideras que has trabajado?

$\square$ Causas y consecuencias de la pobreza 
Derechos humanos

Distribución de la riqueza

Medidas para acabar con la pobreza

Cooperación para el desarrollo

Otro:

1.2 ¿En qué asignatura has trabajado estos temas?

1.3 ¿Cómo has trabajado estos temas? (tema de la asignatura, proyectos de la asignatura, Iturrama Solidario, Iturrama Verde, debates, películas, textos...)

1.4 Teniendo en cuenta los temas tratados, indica con qué profundidad consideras que has tratado la pobreza en el instituto:

Gran profundidad

Profundidad elevada

Profundidad media

Profundidad baja (se menciona de manera esporádica)

No se habla

\section{ODS 2: Hambre cero}

2.1 De los siguientes temas relacionados con el hambre, ¿cuáles consideras que has trabajado?

$\square$ Causas y consecuencias del hambre

$\square$ Opciones de ayudar. Organizaciones

Distribución del hambre en el mundo

Agricultura sostenible

Otro:

2.2 ¿En qué asignatura has trabajado estos temas?

3.3 ¿Cómo has trabajado estos temas? (tema de la asignatura, proyectos de la asignatura, Iturrama Solidario, Iturrama Verde, debates, películas, textos...)

1.4 Teniendo en cuenta los temas tratados, indica con qué profundidad consideras que has tratado el hambre en el instituto:

Gran profundidad

Profundidad elevada

Profundidad media

Profundidad baja (se menciona de manera esporádica)

No se habla

\section{ODS 3: Salud y bienestar}

3.1 Indica si habéis trabajado alguno de los siguientes temas relacionados con la salud y el bienestar:

$\square$ Enfermedades mentales 
Consecuencias de la discriminación

Consecuencias de la droga y el alcohol

$\square$ Cómo mejorar la salud mental

$\neg$ Enfermedades de transmisión sexual

Enfermedades más graves en el mundo

3.2 ¿En qué asignatura has trabajado estos temas?

3.3 ¿Cómo has trabajado estos temas? (tema de la asignatura, proyectos de la asignatura, Iturrama Solidario, Iturrama Verde, debates, películas, textos...)

3.4 Teniendo en cuenta los temas tratados, indica con qué profundidad consideras que has tratado la salud y el bienestar en el instituto:

Gran profundidad

Profundidad elevada

Profundidad media

Profundidad baja (se menciona de manera esporádica)

No se habla

\section{ODS 4: Educación de calidad}

4.1 Indica de los siguientes temas aquellos que habéis trabajado:

$\square$ Situación de la educación en distintos lugares del mundo

$\square$ Opciones de estudio y salidas laborales

4.2 ¿En qué asignatura has trabajado estos temas?

4.3 ¿Cómo has trabajado estos temas? (tema de la asignatura, proyectos de la asignatura, Iturrama Solidario, Iturrama Verde, debates, películas, textos...)

4.4 Teniendo en cuenta los temas tratados, indica con qué profundidad consideras que has tratado la educación en el instituto:

Gran profundidad

Profundidad elevada

Profundidad media

Profundidad baja (se menciona de manera esporádica)

No se habla

\section{ODS 5: Igualdad de género}

5.1 Indica cuál de estos temas habéis tratado en clase:

\section{Estereotipos}

$\square$ Causas actuales e históricas

Diferencias laborales

$\square$ Lenguaje sexista

Diferencias de género por el mundo 
$\square$ Otro:

5.2 ¿En qué asignatura has trabajado estos temas?

5.3 ¿Cómo has trabajado estos temas? (tema de la asignatura, proyectos de la asignatura, Iturrama Solidario, Iturrama Verde, debates, películas, textos...)

5.4 Teniendo en cuenta los temas tratados, indica con qué profundidad consideras que has tratado la igualdad de género en el instituto:

Gran profundidad

$\square$ Profundidad elevada

$\square$ Profundidad media

$\square \quad$ Profundidad baja (se menciona de manera esporádica)

$\square \quad$ No se habla

5.5 Siguiendo esta escala, ¿cómo valoras el trabajo que realiza el instituto contra las desigualdades de género?

Muy buen trabajo. Se ha notado gran cambio

Buen trabajo pero le falta alguna actuación

Mejorable en todos los sentidos

No se nota el trabajo realizado

Mal encaminado

5.6 Explica tu respuesta:

\section{ODS 6: Agua limpia y saneamiento}

6.1 Relacionado con el agua, indica los temas que tratáis en clase:

$\square$ Contaminación del agua

Escasez del agua

Distribución del agua en el mundo

Huella hídrica personal

$\square$ Agua virtual (utilizada en producción)

Otro:

6.2 ¿En qué asignatura has trabajado estos temas?

6.3 ¿Cómo has trabajado estos temas? (tema de la asignatura, proyectos de la asignatura, Iturrama Solidario, Iturrama Verde, debates, películas, textos...)

6.4 Teniendo en cuenta los temas tratados, indica con qué profundidad consideras que has tratado el agua en el instituto:

Gran profundidad

Profundidad elevada

Profundidad media

Profundidad baja (se menciona de manera esporádica) 
No se habla

\section{ODS 7: Energía asequible y no contaminante}

7.1 Habéis tratado en alguna asignatura las fuentes de energía renovables y no renovables?

$\square$ Sí

$\square$ No

7.2 ¿En qué asignatura has trabajado estos temas?

7.3 ¿Cómo has trabajado estos temas? (tema de la asignatura, proyectos de la asignatura, Iturrama Solidario, Iturrama Verde, debates, películas, textos...)

7.4 Teniendo en cuenta los temas tratados, indica con qué profundidad consideras que has tratado el tema:

Gran profundidad

Profundidad elevada

Profundidad media

Profundidad baja (se menciona de manera esporádica)

No se habla

\section{ODS 8: Trabajo decente y crecimiento económico}

8.1 Indica cuál de estos temas habéis tratado en clase:

$\square$ Situación del desempleo

Importancia del emprendimiento

$\square$ Crecimiento económico sostenible

$\square$ Economía personal: ahorros, inversión

Condiciones laborales y desigualdades salariales

Otro:

8.2 ¿En qué asignatura has trabajado estos temas?

8.3 ¿Cómo has trabajado estos temas? (tema de la asignatura, proyectos de la asignatura, Iturrama Solidario, Iturrama Verde, debates, películas, textos...)

8.4 Teniendo en cuenta los temas tratados, indica con qué profundidad consideras que has tratado el mercado laboral en el instituto:

Gran profundidad

Profundidad elevada

Profundidad media

Profundidad baja (se menciona de manera esporádica)

No se habla

ODS 9: Industria, innovación e infraestructura

9.1 Indica cuál de estos temas relacionados con las mejoras que trae la tecnología al medio ambiente habéis tratado:

Transporte eléctrico 
Tecnología y producción: menos contaminación

Energías renovables.

9.2 ¿En qué asignatura has trabajado estos temas?

9.3 ¿Cómo has trabajado estos temas? (tema de la asignatura, proyectos de la asignatura, Iturrama Solidario, Iturrama Verde, debates, películas, textos...)

9.4 Teniendo en cuenta los temas tratados, indica con qué profundidad consideras que has tratado estos temas en el instituto:

Gran profundidad

Profundidad elevada

Profundidad media

Profundidad baja (se menciona de manera esporádica)

No se habla

\section{ODS 10: Reducción de desigualdades}

10.1 Indica qué tipo de desigualdad habéis tratado en el instituto:

$\square$ Desigualdad de género

Desigualdades por religión

Desigualdades económicas

Orientación sexual

Otro:

10.2 ¿En qué asignatura has trabajado estos temas?

10.3 ¿Cómo has trabajado estos temas? (tema de la asignatura, proyectos de la asignatura, Iturrama Solidario, Iturrama Verde, debates, películas, textos...)

10.4 Teniendo en cuenta los temas tratados, indica con qué profundidad consideras que has tratado la reducción de las desigualdades en el instituto:

Gran profundidad

Profundidad elevada

Profundidad media

Profundidad baja (se menciona de manera esporádica)

No se habla

\section{ODS 11: Ciudades y comunidades sostenibles}

5.1 ¿Habéis hablado en alguna asignatura sobre ciudades sostenibles? (por ejemplo, se han pregunta sobre cómo hacer que las ciudades sean accesibles para todos sin importar las diferencias de capacidad, sexo, edad..., que haya transporte sostenible, huertos urbanos...)

$\square$ Sí

$\square$ No

5.2 ¿En qué asignatura has trabajado estos temas? 
5.3 ¿Cómo has trabajado estos temas? (tema de la asignatura, proyectos de la asignatura, Iturrama Solidario, Iturrama Verde, debates, películas, textos...)

5.4 Teniendo en cuenta los temas tratados, indica con qué profundidad consideras que has el tema de las ciudades sostenibles en el instituto:

Gran profundidad

Profundidad elevada

$\square$ Profundidad media

$\square$ Profundidad baja (se menciona de manera esporádica)

$\square \quad$ No se habla

\section{ODS 12: Producción y consumo responsables}

12.1 Indica cuál de estos temas habéis tratado en clase:

$\square$ Diferentes medios de transporte

Consumo responsable

$\square$ Energía renovable

$\square$ 3R: reciclar, reutilizar, reducir

$\square$ Etiquetado de los productos

12.2 ¿En qué asignatura has trabajado estos temas?

12.3 ¿Cómo has trabajado estos temas? (tema de la asignatura, proyectos de la asignatura, Iturrama Solidario, Iturrama Verde, debates, películas, textos...)

12.4 Teniendo en cuenta los temas tratados, indica con qué profundidad consideras que los habéis trabajado:

Gran profundidad

Profundidad elevada

Profundidad media

Profundidad baja (se menciona de manera esporádica)

No se habla

\section{ODS 13: Acción por el clima}

13.1 Indica cuál de estos temas relacionados con el cambio climático habéis tratado:

Causas y consecuencias

Efecto invernadero

Medidas a tomar

Otro:

13.2 ¿En qué asignatura has trabajado estos temas?

13.3 ¿Cómo has trabajado estos temas? (tema de la asignatura, proyectos de la asignatura, Iturrama Solidario, Iturrama Verde, debates, películas, textos...) 
13.4 Teniendo en cuenta los temas tratados, indica con qué profundidad consideras que los habéis trabajado:

Gran profundidad

Profundidad elevada

Profundidad media

Profundidad baja (se menciona de manera esporádica)

No se habla

\section{ODS 14: Vida submarina}

14.1 ¿En alguna asignatura tratáis las consecuencias de la actividad humana en la vida submarina (pesca, contaminación...)?

$\square$ Sí

$\square$ No

14.2 ¿En qué asignatura has trabajado estos temas?

14.3 ¿Cómo has trabajado estos temas? (tema de la asignatura, proyectos de la asignatura, Iturrama Solidario, Iturrama Verde, debates, películas, textos...)

14.4 Teniendo en cuenta los temas tratados, indica con qué profundidad consideras que los habéis trabajado:

Gran profundidad

Profundidad elevada

Profundidad media

Profundidad baja (se menciona de manera esporádica)

No se habla

\section{ODS 15: Vida y ecosistemas terrestres}

15.1 ¿En alguna asignatura habéis hablado de las consecuencias de la actividad humana en los ecosistemas terrestres, así como la deforestación, que desaparezcan las especies...?

$\square$ Sí

$\square$ No

15.2 ¿En qué asignatura has trabajado estos temas?

15.3 ¿Cómo has trabajado estos temas? (tema de la asignatura, proyectos de la asignatura, Iturrama Solidario, Iturrama Verde, debates, películas, textos...)

15.4 Teniendo en cuenta los temas tratados, indica con qué profundidad consideras que los habéis trabajado:

Gran profundidad

Profundidad elevada

Profundidad media

Profundidad baja (se menciona de manera esporádica)

No se habla 


\section{ODS 16: Paz, justicia e instituciones sólidas}

16.1 ¿En alguna asignatura habéis hablado sobre temas como paz, justicia, leyes y derechos humanos?

$\square$ Sí

$\square$ No

$\square$ Diferentes medios de transporte

Consumo responsable

Energía renovable

3R: reciclaje, reutilizar, reducir

Etiquetado de los productos

16.2 ¿En qué asignatura has trabajado estos temas?

16.3 ¿Cómo has trabajado estos temas? (tema de la asignatura, proyectos de la asignatura, Iturrama Solidario, Iturrama Verde, debates, películas, textos...)

16.4 Teniendo en cuenta los temas tratados, indica con qué profundidad consideras que los habéis trabajado:
Gran profundidad
Profundidad elevada
$\square$ Profundidad media
$\square \quad$ Profundidad baja (se menciona de manera esporádica)
$\square \quad$ No se habla

\section{ODS 17: Alianzas para lograr objetivos}

17.1 Indica cuál de estos temas habéis tratado en clase:

Los tratados y organizaciones mundiales que existen para conseguir todos los objetivos planteados en los otros puntos.

$\square$ Diferentes organizaciones no gubernamentales

17.2 ¿En qué asignatura has trabajado estos temas?

17.3 ¿Cómo has trabajado estos temas? (tema de la asignatura, proyectos de la asignatura, Iturrama Solidario, Iturrama Verde, debates, películas, textos...)

17.4 Teniendo en cuenta los temas tratados, indica con qué profundidad consideras que los habéis trabajado:

Gran profundidad

Profundidad elevada

Profundidad media

Profundidad baja (se menciona de manera esporádica)

No se habla 


\section{Últimas preguntas....}

Si has participado en Iturrama Solidario, ¿cómo valoras el proyecto?

4. Aprendí mucho. Muy entretenido y recomendable

3.

2. Está bien pero cambiaría algunas cosas

1

0. No aprendí nada

Explica tu respuesta anterior:

Si has participado en Iturrama Verde, ¿cómo valoras el proyecto?

4. Aprendí mucho. Muy entretenido y recomendable

3.

2. Está bien pero cambiaría algunas cosas

1

0. No aprendí nada

Explica tu respuesta anterior:

¡Muchas gracias por tu participación! 